\title{
What we know about Wikipedia. A review of the literature analyzing the project(s).
}

\author{
Nicolas Jullien*
}

\begin{abstract}
This article proposes a review of the literature analyzing Wikipedia as a collective system for producing knowledge.
\end{abstract}

\section{Introduction.}

Wikipedia project is one of the tremendous successful project of knowledge production ever, with more than 3.5 million articles for the English version and nearly one million visits per day ${ }^{1}$. This is done by the coordination of thousands of people which give their time and their knowledge to construct the article, making this project one of the biggest collective intelligence project ever created $^{2}$. This volunteering online open projects seem to have found original answers to Olson (1965)'s paradox: without direct monetary retribution, there are enough non-free riders to make the project work. However this tremendous success, this project seems to steam, as there is a growing concern about the difficulty to recruit and retain new editors ${ }^{3}$, problem already stressed

\footnotetext{
*LUSSI, Institut Télécom Bretagne \& ICI-M@rsouin. Nicolas.Jullien@telecom-bretagne.eu

${ }^{1}$ For statistic on Wikipedia, visit http://stats.wikimedia.org/EN/, and for an historical presentation, see Lih (2009).

2 Olleros (2008) proposes a good introduction to the encyclopedia and how it has innovated in the production of encyclopedic knowledge.

${ }^{3} \mathrm{http}$ ://en.Wikipedia.org/wiki/Wikihttp://en.Wikipedia.org/wiki/Wikipedia:Areas_for_Reform\#Do_we_ have_a_problem_recruiting_new.2C_or_retaining_current.2C_editors.3Fpedia: Areas_for_Reform\#Do_we_have_ a_problem_recruiting_new.2C_or_retaining_current.2C_editors.3F and http://meta.wikimedia.org/wiki/ Research: Index.
} 
by researchers (Ortega, 2009).

From an Information System research point of view, this example of open knowledge projects should provide useful information on how structuring online open knowledge project for it to succeed $^{4}$, but also for internal organization's projects, as firms are institutions created to allow collaboration (Simon, 1957; March and Simon, 1958), and even defined by Grant (1996) as "institution for integrating knowledge [of its members]". And regarding this function, the wiki tool, allowing distant and sequential collaboration around a structured document seems to be very promising (Hasan and Pfaff, 2006a,c,b). It also, for libraries, a new platform to stock information and knowledge resources, to to promote digital collection and thus to reach new users (Pressley and McCallum, 2008), and today a prominent source of online information, notably for health (Laurent and Vickers, 2009), where false information may have dramatic consequences.

But to be used as a model, how the model works is needed to be better understood. This is need for internal purpose too: the Wikipedia project managers may want to monitor the activity: is the English Wikipedia more efficient than the French one, or are projects (portals) more or less efficient, more or less productive, is there a minimal, an optimal number of editors for an article ${ }^{5}$ ?

And, to quote Crowston et al. (2006, p. 124), to "be able to learn from teams that are working well, we need to have a definition of 'working well"'. To do so, we first rely on the literature of Information System, but also on the literature of knowledge common, to propose a framework of how the elements interact. Then, we propose are review of the existing literature on how Wikipedia works.

\section{Theoretical contributions.}

\subsection{Research questions.}

There are numerous research articles dealing with Wikipedia (7029 articles in the science direct base on October $20^{\text {th }}$ ), notably because this encyclopedia is used as a test base in information and

\footnotetext{
${ }^{4}$ Even if the comparison between different industries must be done very carefully, as shown by Müller-Seitz and Reger (2009) on the comparison between open-source with Open Source car and Wikipedia projects.

${ }^{5}$ For research questions pointed by the Wikimedia foundation, which support the Wikipedia project, see http: //meta.wikimedia.org/wiki/Research: Index.
} 
language processing systems ${ }^{6}$ and information retrieval tasks (Buriol et al., 2006).

This socio-technical project (Bryant et al., 2005; Benker and Nissenbaum, 2006), where the tools used and the rules mediate and shape user activity around open collaborative writing, can be seen as a community of practice (Hara et al., 2010), or even as an aggregation of multiple communities of practice (see, for instance, the analysis of the use of Wikipedia by sport fans by Ferriter, 2009). Regarding its functioning, Okoli (2009); Park (2011); Okoli et al. (2012) may have proposed the most recent review of the literature, which can be split into three main themes (we add recent references to his): motivations to contribute (Nov, 2007), and link between these motivation and the quality of the contribution (Glott et al., 2010a); editorial process or internal organization (Besten and Dalle, 2008; Brandes and Lerner, 2008; Fréard et al., 2010; Kittur et al., 2007b,a; Ortega and Gonzalez Barahona, 2007) and its impact on quality (Viégas et al., 2007a,b; Okoli and Oh, 2007; Stvilia et al., 2008; Carillo and Okoli, 2011), with a majority of article in Information System (IS), Computer Mediated Communication and Computer Supported Cooperative Work; quality and reliability of the production, with a more communication and library science (Denning et al., 2005; Magnus, 2006; Svoboda, 2006; Gorman, 2007; Waters, 2007; Fallis, 2008; Dede, 2008; Fiedler, 2008; Eijkman, 2008; Rector, 2008; Santana and Wood, 2009; West and Williamson, 2009; Royal and Kapila, 2009; liang Chen, 2010) and teaching orientation (Callis et al., 2009; Haigh, 2011), with more critic studies before 2007, even if Giles (2005) is the first publication which proposed a comparison of both Wikipedia and classical encyclopedia, quite in favor of the first ${ }^{7}$.

As we want to study the findings of all these articles, we need a more general framework of understanding of the functioning of these communities, before going deeper in their analysis.

\subsection{A framework to analyze the project.}

Carillo and Okoli (2011)'s framework (figure 1, page 5) is rather extensive on the input and process part, but less complete on the output part, as they only focus on the declared quality of the articles

\footnotetext{
${ }^{6}$ See, for instance, the researches conducted at University of Amsterdam, http://ilps.science.uva.nl/search/ node/Wikipedia.

${ }^{7}$ For an example of the dialog between Librarian and Wikipedian, one can look at the Wikipedia Loves Libraries manifestation, http://en.Wikipedia.org/wiki/Wikipedia:Wikipedia_Loves_Libraries. For an overlook at the principal critics of Wikipedia, being pertinent or not, see O'Neil (2010).
} 
by Wikipedia ("regular article with no nomination, featured article nominees that were not accepted, and featured articles").

They did not explicitly take into account the retroactions, and did not distinguish between the outcomes of the project and the specific outcomes for the participants. One of the main differences between these online projects ("communities") and the other common good productive communities is that the production outcomes (the pieces of software, the Wikipedia articles) are available to all, when the producers may have extra outcomes (and costs) to their involvement, as we showed in Jullien et al. (2011).

For instance, Crowston et al. (2006), followed by Lee et al. (2009), propose indicators to analyze the group production (they name "system creation"), and complete this model on two points. Relying on DeLone and McLean (1992, 2002, 2003), they proposed indicators to link the concrete outputs (here article, in their case, open source software) to the user's satisfaction. In their study, they also refer to Hackman (1987), to show the importance, as an output, of taking into account the producers (or contributors) feedback, and the process of development to have a global view of the outputs of such open online projects. They finally rely on Seddon (1997) to extend Delone and McLean's model on the user side, with the concept of "perceived usefulness", which echoes psychosociological studies on the adoption of systems by users, such as Technology acceptance model by Davis (1989) and its extensions (Venkatesh et al., 2003).

Finally, Wikipedia is an example of a "knowledge commons" (Hess and Ostrom, 2006b). These authors proposed a framework to understand the production of such common, we present in figure 2 , page 6 .

This leads us to a more global scheme (figure 3, page 7), where inputs are the providers as actors, the process the action arena (action situations) and mainly the patterns of interaction, and the outputs, the outcomes, view from different viewpoints, users, but also producers (providers in Hess and Ostrom's terminology), and which can be seen as an extension of the model proposed by Zhao and Bishop (2011, p. 720).

Of course, as mentioned by the authors quoted, and what clearly appears on Hess and Ostrom's framework, the outcomes influence the inputs. The providers are given opportunities by their 
Fig. 1: Model of group processes in open content communities, from Carillo and Okoli (2011), figure 1 page 210 .

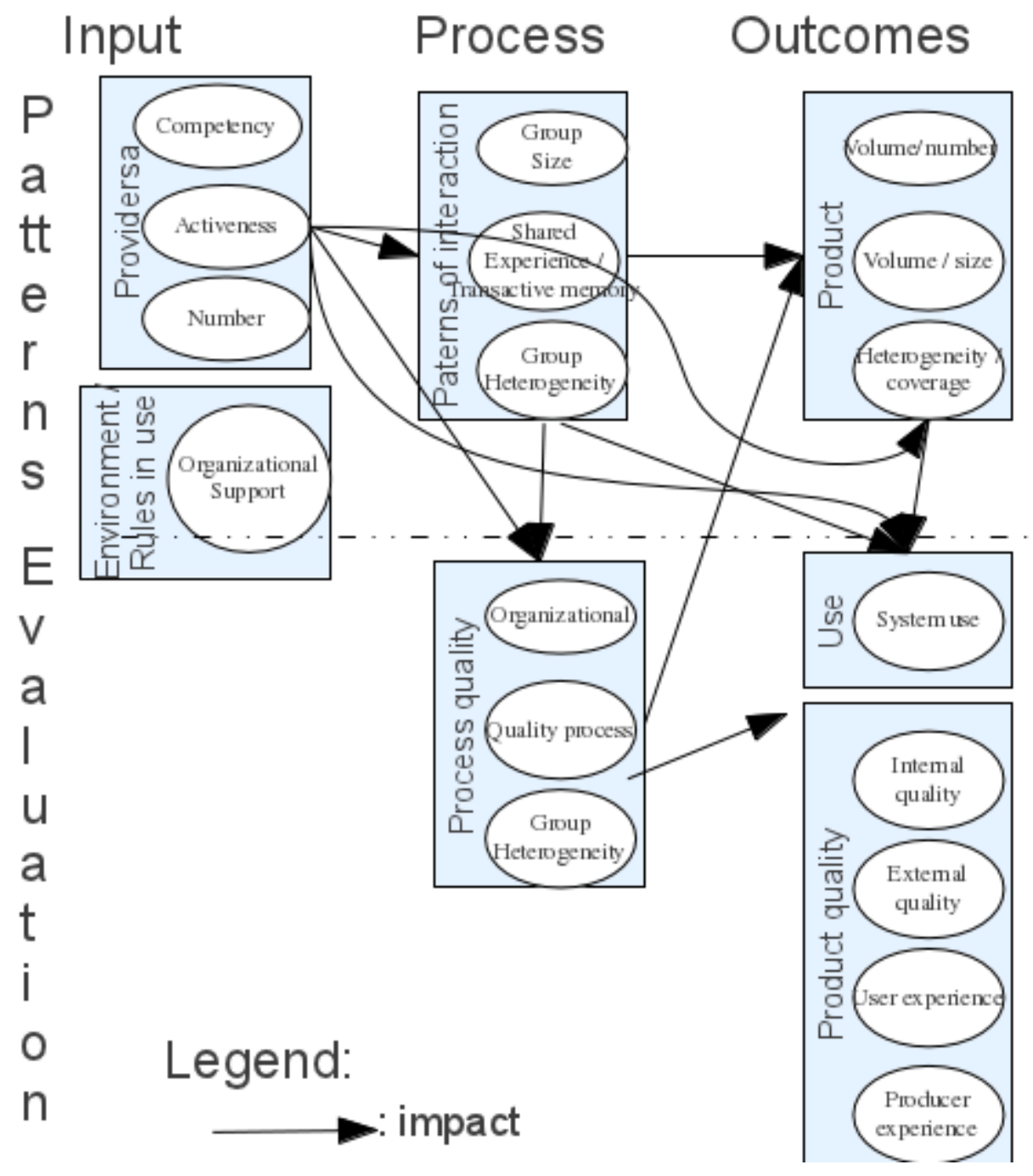


Fig. 2: Institutional Analysis and Development framework for knowledge commons (Hess and Ostrom, 2006a, p. 44)

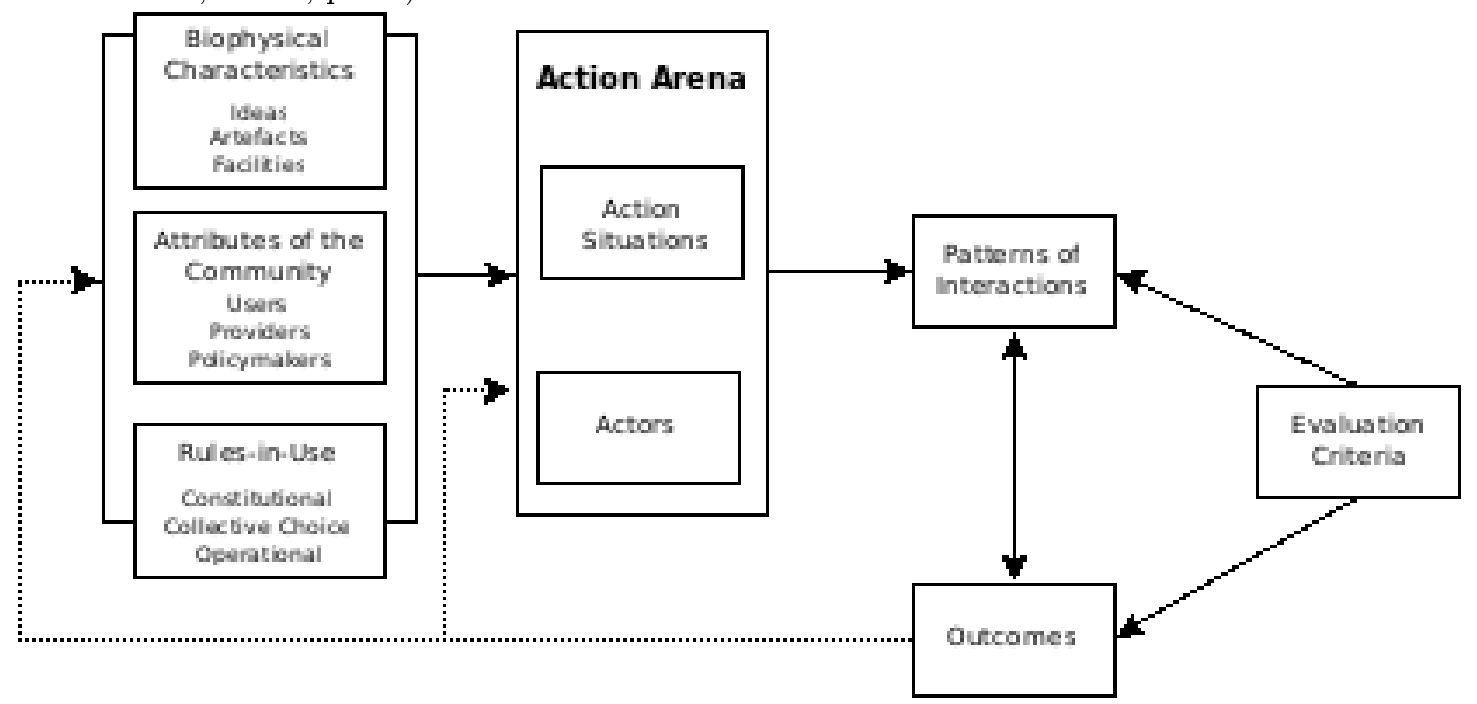

participation, leading them to potentially involve more themselves in the project; the users may also, by interacting with the system, become providers: for instance, Lih (2004) shows that articles cited by the press see the number of contributors increasing. We will come back to this point in the conclusion of the article, but we argue that, before looking at how this retro action loop works and impact the system, we have to understand the system, which is the main goal of this work.

\subsection{The scientific production on Wikipedia.}

In concrete this means that a large part of the literature is out of the scope of this article: neither the impact of the project on the environment (the doted line in Figure 3), such as how it is used to comply professional tasks (by the students, the researchers, the people in the industry), nor the analysis of the propositions to improve the tools (using it on mobile, creating a 3D Wikipedia), nor the use of Wikipedia as a database for information retrieval test will be looked at here. This restriction does not provide any restriction in terms of scientific scope (except for algorithm research, data-mining, computational intelligence, semantic, information retrieval), and we decided not to restrain our research to a particular field as the topic is covered by various fields and as our goal 
Fig. 3: Inputs, process and outcomes of online open projects.

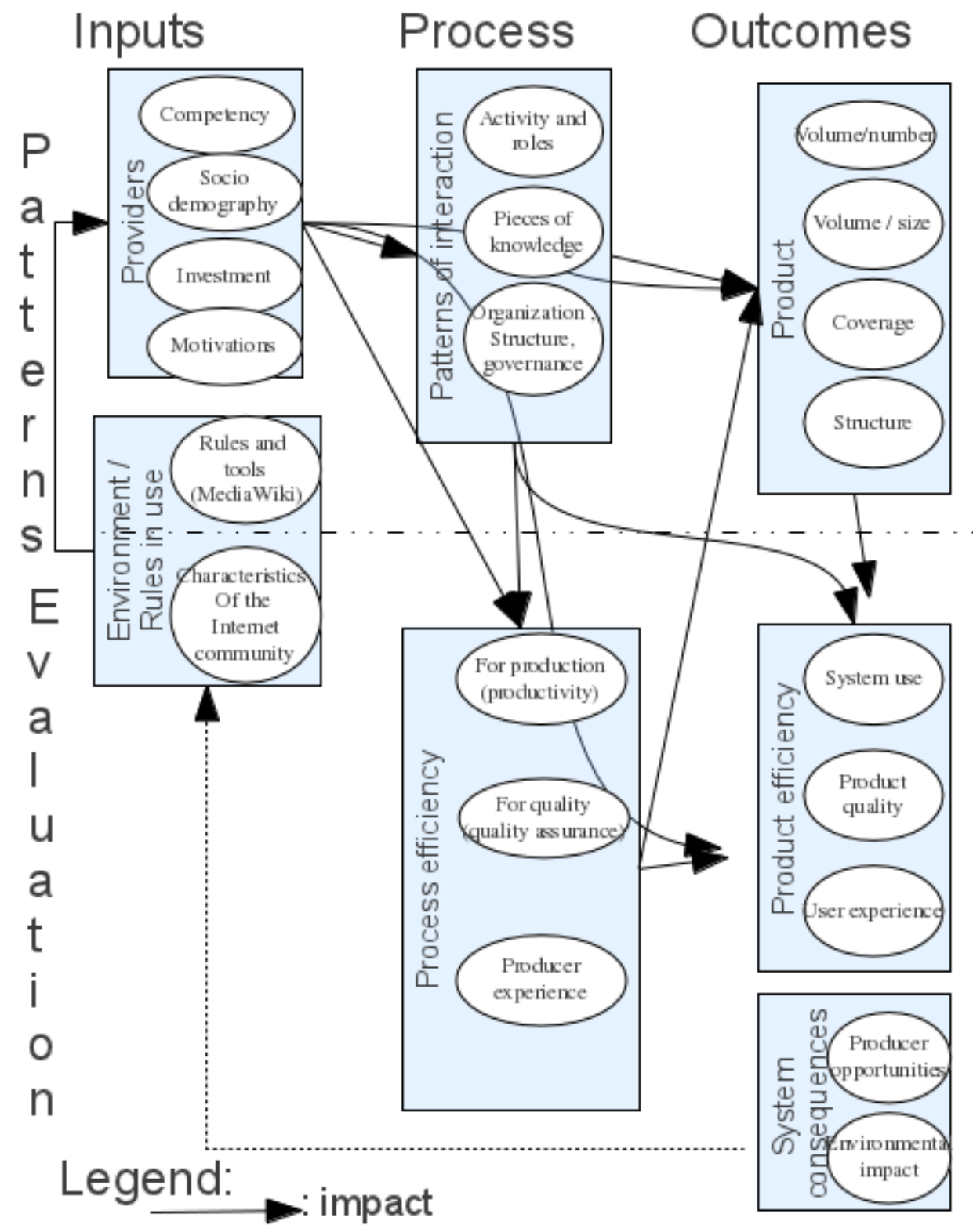


was to have an as extensive as possible view of the Wikipedia phenomenon.

This is also the reason why we did not restrain to articles published in journals, but added conference proceedings and books. However, we restrain to papers published in English, French and Spanish as we needed to understand the topics covered, and papers available before February 2012 .

We thus opted for a search strategy with high sensitivity (Dieste and Padua, 2007), meaning that we searched with the keyword "Wikipedia" (or "Wikipédia)" in the digital libraries (and not "Wikipedia organization", "Wikipedia evaluation" or other terms which would have restraint the search), in the title or keywords, but not in full text or in the summary as we wanted that Wikipedia was specifically studied and not just an example given in the text.

The searches were conducted in December 2011 on Scorpus and WebofScience databases. Bibliography for all the publications was stored in the external bibliography system (CSV file and then Bibtex $)^{8}$. We rejected introductions of panels, conferences, book reviews, news flashes. We also deleted conference articles which were redundant in the base, mostly because they had been presented in conferences before been published in a journal, which let us with a bit less than 300 articles we read. Finally, we compared and completed the list obtained looking at the list of the "academic studies on Wikipedia" maintained by the project itself 9 .

The rest of the article presents and discusses their findings, and is organized accordingly to the framework proposed in figure 3 .

\footnotetext{
8 The query on Scopus was:

(TITLE(Wikipedia) OR TITLE(Wikipédia) OR KEY(Wikipedia) OR KEY(Wikipédia)) AND (LIMITTO(DOCTYPE, "cp") OR LIMIT-TO(DOCTYPE, "ar")) AND (LIMIT-TO(LANGUAGE, "English") OR LIMITTO(LANGUAGE, "Spanish") OR LIMIT-TO(LANGUAGE, "French")) AND (EXCLUDE(EXACTKEYWORD, "Semantics") OR EXCLUDE(EXACTKEYWORD, "Information retrieval") OR EXCLUDE(EXACTKEYWORD, "Natural language processing systems") OR EXCLUDE(EXACTKEYWORD, "Ontology") OR EXCLUDE(EXACTKEYWORD, "Computational linguistics")) AND (EXCLUDE(SUBJAREA, "MATH")) AND (EXCLUDE(EXACTKEYWORD, "Artificial intelligence") OR EXCLUDE(EXACTKEYWORD, "Data mining"))

${ }^{9}$ en.wikipedia.org/wiki/Wikipedia:Wikipedia_in_academic_studies
} 


\section{Inputs.}

\subsection{Environment, rules in use.}

Actually, speaking of the Wikipedia project can be viewed as a short-path, as each language proposes a version, and has its own collection of articles, more or less common with the English version.

Hecht and Gergle (2010a) studied 25 language projects and found that the articles present in all the projects represent only $1 \%$ of the total, when $74 \%$ of the articles were present in one language only. For instance, Callahan and Herring (2011) showed that the famous persons for the English and the Polish Wikipedia are not the same ${ }^{10}$.

Pfeil et al. (2006), analyzing the way French, German, Dutch and Japanese contributed to the article "game", show a correlation between Hosfstede's cultural dimensions (Hofstede, 1991; Hofstede and McCrae, 2004) and the way people perform different kinds of actions in the writing of the article (number of correction, deletion, contributions). For instance, there are statistically significant more courtesy behaviors in the large Wikipedias that in the small ones (in terms of number of articles) and in Eastern Wikipedias than in Westerns ones (Hara et al., 2010, in a comparative study of the English, Hebrew, Japanese, and Malay Wikipedias). Stvilia et al. (2009) compared the English Wikipedia Feature Article quality process with the one of the Arabic and the Korean Wikipedia. However the small size of the sample for the two last (91 for the Arabic and 25 for the Korean), they showed that for almost all the criteria used by the users to evaluate the $\operatorname{articles}^{11}$, there are strong variations between the three projects (at the date of the dumps copy, June 2008). There are strong variation too, in the representation of the knowledge (see, for instance, the study by Hammwöhner, 2007, part 6, p. 10, on how categories are subordinate in various European languages). As early as 2005, Voss (2005) noted a strong variation in the number of edit made by anonymous between languages Wikipedia (10\% in the Japanese one, and $40 \%$ in the Italian one at the end of 2004), whereas the number of edit by people distribution was quite similar.

\footnotetext{
${ }^{10}$ See also the differences in the periods of contribution, where some language Wikipedias more contributed during the weekdays, such as the English one, and other during the week-end (Japanese, for instance) in (Yasseri et al., 2012).

${ }^{11}$ Well-written, Comprehensive, Factually accurate, Neutral, Stable, Consistent with the style guidelines, Images, Appropriate focus and length for the English and the Arabic, Well-written, Appropriate Length, Neutral, Accurate, Links, Images for the Korean).
} 
Some projects may have specific difficulties, making the path of evolution barely comparable to the others, such as the Chinese Wikipedia, which has had to solve the conflict between different writing forms (Liao, 2009), or small number of speakers Wikipedia, which are quite empty of real articles, as shown by van Dijk (2009). This author also show the importance of the Internet access, but also of the number of people able to translate articles from the English to explain the difference in Wikipedia growth ${ }^{12}$, a result also stressed by Stvilia et al. (2009). Finally, as Liu and Iyer (2007) pointed out, these variations may be also due to variations in age and scale of the projects. As Marwell and Oliver (1993); Oliver et al. (1985) explained, in collective projects at the initial stage, people are few and efforts costly, in the diffusion phase, the number of participants grows as their efforts are rewarding, but with increasing need for coordination, and the mature phase, some inefficiency may appear as the contributors are more numerous than the work needed (note that this has been empirically tested in the case of open online communities by Alluvatti et al., 2011). if until 2006, and according to Wales, the English Wikipedia was written by a small group of editors (talk at Stanford University in 2006, cited in Swartz, 2006), as early as 2006, Buriol et al. (2006) showed that there were some indications of a permanent regime (they call "maturity"): for instance the constance of the average edits per users, or the "high correlation between PageRank and indegree, indicating that the microscopic connectivity of the encyclopedia resembles its mesoscopic properties" (p. 8). Suh et al. (2009) confirmed this slowdown for the English Wikipedia. Lam and Riedl (2011) confirmed that the English Wikipedia's production follows a S-shaped curve.

But what these various in projects have in common that healthiness of a language project depends on the characteristics of the Internet community (especially the number of Internet users, and the wealthiness of of the population, according to Rask, 2008), and on the people's competencies (Glott et al., 2010b), especially the number of tertiary educated people within the population (Crowston et al., 2013). The global structure of the project, measured as a network, the nodes being the articles and the links the links between the articles, seems also to be the same, in terms of "degree distributions, growth, topology, reciprocity, clustering, assortativity, path lengths, and triad significance profiles", at least for the main projects (Zlatić et al., 2006). People also seem to

12 On that aspect, he relied on the analysis of the Indonesian Wikipedia made by Soekatno and Giri (2005) 
contribute during the same period of time of the day (between 1pm and $11 \mathrm{pm}$, still in Yasseri et al., 2012). Finally, Zhao and Bishop's Delphi study (2011 p. 725), points that the factors underlined by Wikipedia researchers to explain Wikipedia's success are, in addition to its success, the rules in use (especially the ones which promote communications) and the technical structure which supports these rules and facilitates the editing.

As pointed out by Hess and Ostrom (2006b), as by the actor network theory Akrich et al. (2006); Latour (2005), the artifacts, or the tools used by the online communities are important to understand how this community can work. Or, to quoteNiederer and van Dijck (2010, p. 6), "Wikipedia [is] a gradually evolving sociotechnical system that carefully orchestrates all kinds of human and non-human contributors by implementing managerial hierarchies, protocols and automated editing systems". Two tools seem to be of particular importance to understand what Wikipedia is: first of all, the program allowing to edit and manage the contributions, the MediaWiki. Several structuring features of the Wikipedia collaborative organization are due to this software (Prasarnphanich and Wagner, 2009), such as the collective editing, but also the existing of a talk page for each articles, or the way links are made between articles and to the exterior. This tool suffers certain limitations, from a content management orthodox point of view, according to Doyle (2008): there "are clueless about today's content management best practices like content reuse, modularity, structured writing, and information typing". But as emphasized by Ciffolilli (2003), in a transaction cost theory based analysis of Wikipedia, "Wiki technology in a way literally cancels transaction costs for editing and changing information". This is a bit optimistic, as people have to understand how the changes are stored and still have to discuss to content (see the section 4, page 18 on that aspect), but it surely drop this cost (Rafaeli and Ariel, 2008, p. 252), and also drop the cost of degradation, or "graffiti attacks" (Ciffolilli, 2003), as the tool keeps memory of the former versions and makes it easy reversing. It also helps people, and especially the editors, in the organization and in the structuring of their tasks (Sundin, 2011).

However the importance of this wiki-based technical platform (Niederer and van Dijck, 2010), it seems that, as the project has grown up, the socio-technique community evolved 'from an informal trust-based community with few formal roles to a socio-technique community where the 
social mechanisms, and not the software architecture, supports knowledge management processes" (Jahnke, 2010). Even if it seems paradoxical, this is well illustrated by a second software tool which has gained growing importance with the success of Wikipedia, the bot. Because, a explained by Geiger (2011, end of p. 5 and following): 'Bots, like infrastructures in general, simultaneously produce and rely upon a particular vision of how the world is and ought to be, a regime of delegation that often sinks into the background [...]"

Bots are responsible for most of the publications of articles in endangers language Wikipedias (Niederer and van Dijck 2010, p. 12 based on Devereaux et al., 2008), resulting that most of these articles are empty (van Dijk, 2009). In the same time, still as shown by Niederer and van Dijck (2010) on the list of the USA towns, the automate creation of articles facilitates the completion of these articles in the future. The role played by these automate tools is well illustrated by Geiger and Ribes's analysis (2010) of the vandal fighting, and of the role played by software in this task: in a comparison with the analysis of ship navigation by Hutchins (1996), they show how these tools implement human decision facilitating their execution (the detection of task considered as vandalism, or the automatic and comprehensive creation of a set of information) and their management by automating the rules (gradation in the sanction, formated messages), making these tasks "mundane". But still pointed out by these authors, the definition of vandalize and the punishments remain a moral choice, and the humans implement the rules by programing these tools. Thus, these tools also are discussed Geiger (2011, end of p. 5 and following) "- that is, until they do not perform as expected and generate intense controversies".

These rules are numerous, increasing in number and complexity (Butler et al., 2008, analyzing the English Wikipedia's rules), and ranging from the the more formal and explicit (intellectual property rights) to the more informal.

First of all, it must be stressed that, as for software, articles are protected by copyright laws, and that it is this protection which grants the producer to license (in the Latin sense, authorize) the user to use it. Here, this protection is used to "copyleft" the use, to quote Stallman, but it comes also with obligations. The "Creative Commons Attribution-ShareAlike" License, used for Wikipedia, allow to use, to change, but if redistributed, the work built upon the article has to be 
redistributed under the same terms and conditions ${ }^{13}$. If this protection is juridically efficient is matter of debate (seeWielsch, 2010, on that question), but this frameworks the vision people have about the project and of its openness. Another legal based characteristics of Wikipedia is that the name is a registered trademark of the Wikimedia Foundation (non-profit organization), which also owns the technical infrastructure which operates the service (servers). So, if this foundation does not own the content, its own the right to ultimately decide what can be posted under the name of Wikipedia and on its server, and its board is only for a part elected by the participants in Wikipedia ${ }^{14}$. Quite surprisingly regarding their importance, especially in the open source world, we can not find study of how Foundations manage open online communities (Reagle Jr., 2010, chapter 6, mentions this point however and gives a good start for Wikipedia.). It is however clear that the leaders of these projects play an important role in defining its goals and orientation (see Crowston et al., 2010 for an analysis of this aspect), especially in the case of Wikipedia, where one of the two founders, Jimmy Wales, gave the vision (Reagle Jr., 2010, chapter 1) and is still considered as the leader of the project, is the ultimate decision maker (Reagle Jr., 2010, chapter 6, which deals with Wikipedia leadership) and has a permanent seat in the board of trustees as founding member.

He is at the origin of the tables of law of the project, the "five pillars" of Wikipedia" ${ }^{15}$, defining the product (online encyclopedia) and its scope (neutral point of view, no original research, accuracy, which are the three core policy guiding the organization, according to Reagle Jr., 2010), the producers and the users (anyone), and the process of production (interaction and good faith), knowing that, as every project organization, it has to be adaptable (no firm rules). Cardon and Levrel (2009); Cardon (2012) propose a deep analysis of these explicit and implicit rules, showing that these rules aim at involving any participant in the monitoring and discussion of others' contribution, designing a procedural organization (we will come back latter to this point). In other words, this organization would be an attempt to create a "supportive environment" (Reagle Jr. 2010b, basing on Gibb, 1961), i.e. an environment which privileges "description (vs evaluation), problem orientation, spontaneity, empathy, equality, provisionalism". However, this also means

\footnotetext{
13 http://creativecommons.org/licenses/by-sa/3.0/

14 http://wikimediafoundation.org/wiki/Board_of_Trustees

15 For the English: http://en.Wikipedia.org/wiki/Wikipedia:Five_pillars, but they are available in practically any language supported by the project.
} 
that the the foundations of the organization are constantly renegotiated by the people (and by their behavior), leading ambiguity to be "at the heart of the policy process on Wikipedia" (Matei and Dobrescu, 2011). It works because rules are mainly integrated by the persons in charge (this is part of the process of involvement into the project), which allows in the same time the maintaining of a common goal (the ideal of consensus building and discussion) and the growing decentralization of the day-to-day decisions due to the growing size of the project (Forte et al., 2009).

And when a very deep conflict appears, such as the case of the Jyllands-Posten Muhammad Cartoon Controversy (Morgan et al., 2011) it seems that the appeal to the values-in-practice, i.e. freedom of information over multicultural inclusiveness (ibid, p. 7), thus to the common rules, is a very powerful mean to gain the decision.

The question is then to understand how this system is organize to attract and retain these people, make them collaborate, and deal with the growth of the population. As in many situations, the studies balance between two positions: exploiting the data available, and the fact that they are complete on the contribution, to provide general global results on the participants, the products and the process, or deepening the understanding beyond what is visible, thus trying to collect new data, via exploratory methods, and compensating the loose in representativity by a better understanding of the why or the how people do things. Of course both are needed and complementary but, in general, we will present the more global studies first, to have a global picture.

\subsection{Why do they participate?}

As Prasarnphanich and Wagner (2011) showed, Wikipedia is an aggregation of contributors with varying levels of resources and interests, verifying in that aspect too the fact that it follows the critical mass theory (Marwell and Oliver, 1993$)^{16}$. Most of the studies we read, minus one, looked at the motivations to do positives things participating in Wikipedia. Quite strangely, we did not find any study on the reasons for leaving Wikipedia, while they would be interesting to understand how the contribution and the benefits it brings change, but also, if it is possible, to prevent these disaffections. Even if, according to the authors, the study is preliminary, Ortega and Izquierdo-

${ }^{16}$ For a formal model of this phenomenon, see Rahman (2008) 
Cortazar (2009), using survival analysis techniques, showed that the mean time of participation to the encyclopedia is between 200 and 400 days for the top ten projects (with a median between 75 and 200 days), quite an important turnover.

This single study not looking at the motivations to do positive things is by Shachaf and Hara (2010) and looks at troll makers' activity. It shows more social disorder than real motivations. However, these activities impact on the information available (we will discuss more this aspect in section 4) and it would be interesting to better understand how to cope with these behaviors. It relayed on indirect information about the four trolls they followed, because it was difficult to enter in contact with them, as they hide their real identity. But this is a common difficulty of the studies working on Wikipedians' motivation. It very hard to be accurate in the same time on what people do and why they do it, as these pieces of information come from different origins, because there is few internal information on the participants' skills, sociological background or motivations: Lam et al. (2011) used users' page gender box and preference setting, for gender studies, and report a gender information rate of only $6.5 \%$ for editors (in the English Wikipedia) ${ }^{17}$.

So, most of the studies collected external data, via surveys, which are hard to connect with an IP number or a Wikipedian login, in order to link them to the internal data about participation. However this difficulty, the studies available provide with a good understanding of the characteristics and of the motivations of the participants.

Glott et al. (2010b) surveyed Wikipedia users (and producers) and measured their competency by the level of study, and by computer skill, and their activeness by the time spent on Wikipedia. Another option for activeness would be to measure the time spent by the participants (users and providers), but this has not been done as far as we know. The quality and the representativeness of these declarative data are hard to verify. However, what these surveys tell us is that contributors are of higher level of education, mostly male, older in mean that Wikipedia users, and that mastering basic computer skill matters to explain contribution ${ }^{18}$. According to Liang et al. (2008), an for

\footnotetext{
${ }^{17}$ Even if Ashton (2011), in a theoretical work, argues that the whole editing and contributing activity is the signature, or the "wikidentity" (term from Mallan and Giardina, 2009) of a person in Wikipedia and should be studied as so.

18 Collier and Bear (2012) relied on the English version of Glott et al.'s survey to study the reasons why female Wikipedia users participate less. Their explanation is that the encyclopedia is a conflicting environment, and that these users have a lower confidence in their expertise.
} 
the Chinese Wikipedia administrators they surveyed, having more personal time, weaker social belongings, or longer Internet surfing time, increase the motivation for being administrators. When the gap is bridged, the socio-demographic variables are significantly less explaining of the difference between contributors: there is, for example, no significant gender difference in editing between registered Wikipedians (in the English Wikipedia, Antin et al., 2011).

In addition to socio-demographic and skills variables, and still using the survey method, AmichaiHamburger et al. (2008) showed that psychological characteristics such as agreeableness, openness, or conscientiousness, are variables to take into account to explain the contribution to Wikipedia. Focusing only on registered users, Yang and Lai (2010) proposed four types of motivation to explain this involvement: intrinsic (internal satisfaction such as the pleasure or the fun to contribute, but also the satisfaction to help by sharing their knowledge, which seems very important for the most involved participants, according to the results of a survey amongst Wikipedia administrators byBaytiyeh and Pfaffman, 2010), extrinsic (image improvement, professional status improvement), external self-concept-based (recognition by others and especially by peers, tested by Zhang and Zhu (2011) on the Chinese Wikipedia), and internal self-concept-based (acting consistently with their vision of themselves). According to their study, self-concept-based motivations explain the most the involvement, followed by intrinsic motivations (personal enjoyment). This is consistent with a precedent study of Wikipedians' motivation by Nov (2007), which proposed the same methodology and the same items.

However these global results, an important point is that the motivations vary over time (Forte and Bruckman, 2005; Bryant et al., 2005), and that if, for the most involved the recognition from the peers ('credit') is an important motivation (ibid), as is the sense of mission (Liang et al. 2008, basing on a survey of Chinese Wikipedia administrators), for most of the (small) contributors, the will to fix mistake is the principal motivation, making these people not strongly committed to the project (Kamata et al., 2010, relying on a survey of Japan Wikipedia contributors), a result Dejean and Jullien (2012) also found for the French Wikipedia contributors. Using a qualitative methodology (20 semi-guided interviews), Antin (2011) showed the large gap between readers (or occasional contributors) and regular ones, especially regarding the feeling of being part of the 
Wikipedia "community" and how this may refrain from participating. This is explained by the fact that there is a process of acculturation to Wikipedia: the future contributors are firstly readers "dipping their toes in to passively participate while learning more about a complex system" (Antin and Cheshire, 2010, but surveying only US college students), even if the quicker the process is, the greater the chance people become active contributors are (Dejean and Jullien, 2012, surveying French Wikipédia's users and contributors, Panciera et al., 2009, analyzing registered contributors' trajectories). This would means that the motivations to participate are more individual and internal and are present since the beginning ${ }^{19}$.

In other words, as for open source (Lakhani and Wolf, 2005; Shah, 2006; Scacchi, 2007) or professional communities (Jullien et al., 2011), this may be an illustration of the idea of a path, or "career" in the community (in the sens given by Becker, 1960, 1963). To skip from correcting a mistake to becoming a regular contributor, or an administrator, would be an additional commitment, which would occur for reasons developed during the attendance of the project as the development of this sense of "community", i.e. the individual acceptance of the rules of the organization, as showed by Pentzold (2011), on his study of the meaning of the term community by the very involved participants of the Wikipedia-1 mailing list (the surveys by Cho et al. (2010) of 223 English Wikipedians, by Ho et al. (2011) on the Chinese Wikipedians, and by Schroer and Hertel (2009) on the German ones all found a link between this "sense of belonging" and the will to contribute). Kittur et al. (2009) also showed how the people modify their practices of contributing when integrating the Wikiproject, toward more administrative tasks, according to the group requirement.

This leads to the definition of the activities and the outputs of this group, or, said differently, the patterns of interaction.

\footnotetext{
${ }^{19}$ Prasarnphanich and Wagner (2009) defended the idea that "altruistic" motivations prevail in Wikipedia, which seems going against this analysis. But in their study they surveyed 60 very involved Wikipedians, so, according to what was said, people for who the sense of the community is the stronger. And the majority of their respondents had mixed motivations.

Regarding the presence of the motivations since the beginning, in addition to Panciera et al. (2009); Dejean and Jullien (2012), already mentioned, a survey of students from U.S. universities contributing to the Wikipedia content as part of their course work showed that "intentions to continue contributing are influenced by the initial attitude towards the class" (Zube et al., 2012).
} 


\section{The process(es), or the patterns of interaction.}

On the contrary, Wikipedia allows to access to a complete set of data about the articles, their evolution, the people who contributed to them, but also to the discussions which occurred before, during and after the contributions. The articles exploring and exploiting this fascinating set of data to better understand how people interact in such an information system to product a public knowledge are mainly threefold: first, the articles focusing on people and on their actions, describing the activity and assessing roles from this activity; second, the articles looking at the "product", the article; and third the process of creation of such pieces of knowledge, with some works looking at the other pieces of knowledge created in Wikipedia (mainly the discussion pages). In general, the studies looking at the global organizational structure rely on statistical analyses of the variables present in the databases (Dump). Following the seminal work of Korfiatis et al. (2006), most of these studies use social network analysis techniques, the nodes being, usually, the people, and the arcs the fact they contribute to the same article or the same talk page. On the article side, the node are the articles and the arcs the fact that they refer to each others (sometimes those two approaches are mixed). When seeking to improve the processes of collaboration, scholars privileged usually more narrowed sets of articles, their evolution and the one of their talk pages, but deepening the analyses of the content produced.

Slattery (2009) used a quite similar segmentation and provides a nice first approach to the main characteristics of these patterns, approach we are developing here.

\subsection{The contributors, their activity and roles (what they do).}

This part is a perfect illustration of the too kind of studies found on Wikipedia. There are, actually, few studies looking at the contributors as deeply as Sundin's one (2011), which presents the day-to-day life of Swedish Wikipedia editors and underlines the importance of the tool (Mediawiki) and of the basic rules structuring the tasks (vandal fighting, verification of sources, improvement of sourcing...) On the other side of the spectrum, Anthony et al. (2009) proposed a quite macroscopic, but also more comprehensive point of view: they separated the contributors into two groups (reg- 
istered and non registered), and analyzed their contribution for the whole English Wikipedia. If they couldn't infer much about the number of people in each groups, they stressed the importance of those anonymous, as they represent, for instance, $20 \%$ of the contributions that remain in the Spanish Wikipedia (Druck et al., 2008). In other words, if most of the best contributions in terms of quality is done by registered users and by a small subset of the whole contributors, a significant number of anonymous users also do provide quality content (Javanmardi et al., 2009).

As explained before, we will first look at the studies relying on the data provided by the project, thus giving a global and comprehensive view of the participants, or at least of the "authors", defined as the people registered in Wikipedia and having done a contribution, because their registration makes it possible to follow their activity (thanks to the data stored in the MediaWiki table user_groups).

Regarding the activity of each of these registered authors, it has been shown that the number of article per authors follows a power law (Voss, 2005), like in open source and in scientific publication (ibid and Maillart et al., 2008; Arafat and Riehle, 2009 regarding open source), something known as the Lotka's law (ibid), as does the number of contributions per person, in all the main language projects (Kittur et al., 2007a; Ortega et al., 2008; Ortega, 2009; Javanmardi et al., 2009; Zhang et al., 2010). However, it seems that the percentage of contribution coming from the users having privileges (administrators of Wikipedia) which are the biggest contributors, is decreasing with the age of the project (Kittur et al., 2007a; Ortega and Gonzalez Barahona, 2007; Ortega et al., 2009). In the other hand, their contributions dominate what people see when visiting Wikipedia (Priedhorsky et al., 2007): 'The top $10 \%$ of editors by number of edits contributed $86 \%$ of the PWVs [persistent word views], and top $0.1 \%$ contributed $44 \%$ - nearly half! The domination of these very top contributors is increasing over time." (p. 5) Laniado and Tasso (2011), completed this point, using English Wikipedia's dump data, finding evidence of "the presence of a nucleus of very active contributors, who seem to spread over the whole wiki, and to interact preferentially with inexperienced users".

This apparent paradox is easy to understand: as Wikipedia, and especially the English language project, became bigger, the editing tasks have increased in complexity (see Fong and Biuk-Aghai, 
2010 for a proposition of classification in terms of semantic complexity of these various type of edits), and have increased also the proportion of non-editing tasks. In other words, participants' types of activity have multiplied. Behind the writing, which can be seen as the emerged part of the iceberg, but also the most important part, for an encyclopedia, are the actions leading to the writing (coordination tasks, discussions on the topic of the project, etc.)

Regarding the edits, Adler et al. (2008b); Druck et al. (2008) may be the ones who proposed the more complex evaluation of authors' editing contributions, based not only on the volume of add-ons, but also of their persistence (what they call the longevity). The interest of this statistical method, which uses dump data, is its ability to be implemented for the all set of authors in a project. It made it possible to identify bots and vandals (Adler et al., 2008b), and provided insights to Anthony et al.'s arguments (2009) that anonymous contributions are important.

Another part of the literature looks at these other activities, not only at the contribution to article writing, but also to discussion and project pages, user talk pages, leading to a typology of participants' behavior, or "social roles"20. This can be seen as a decrease of the quantitative scope (exploitation of the data) toward more qualitative data, in order to increase, to deeper the qualitative understanding of the practices (exploration). We will organize the presentation of the papers this way in the rest of this part.

Ung and Dalle (2010) emerged a "project leader" role, based on project page editing activity (a project leader is the one who does more than $5 \%$ of the edits on a project page). They found a positive correlation between the coordination tasks (editing activities in the talk pages) and the contributions to the article of these leaders.

Iba et al. (2010) looked at a very small set of articles and people, but went deeply into the interaction between those people in the contribution (edits) and then in the talk pages. They used social network analysis, the nodes being the persons and the weighted edges the number of time author B contributes to the same article as author A. Looking at the activity in the talk pages of four very active editors in the start and the building of quality articles ("coolfarmers in their terminology"), they found two types of patterns: "the mediators, trying to reconcile the different viewpoints of

\footnotetext{
${ }^{20}$ For a study of social roles in Online Communities, in addition to Welser et al. (2011), which rely on Wikipedia, see Gleave et al. (2009).
} 
editors, and the zealots, who are adding fuel to heated discussions on controversial topics". They also identified "egoboosters", i.e. people who mainly use Wikipedia to present themselves, which, if being done by adding entries to the encyclopedia, is against the rules.

As for other open source communities such as Python (Barcellini et al., 2008), Harrer et al. (2008); Halatchliyski et al. (2010), both investigating sub-projects (domains) of the German version of Wikipedia, showed the importance, for the construction and the structuring of the knowledge in Wikipedia, of the "boundary spanners", in the sense given by the Sociology of Translation (Callon et al., 1986; Akrich et al., 2006), i.e. those people who are at the intersection of several domains of knowledge and because they have a broader view "are not only responsible for the integration of knowledge from a different background, but also for the composition of the single-knowledge domains. Predominantly they write articles which are integrative and central in the context of such domains."

Huvila (2010), using a ground theory approach via an online opened questions survey to contributors, proposed a classification in five types for the contributors, according to their activities and to the way they find their information (table 1).

Welser et al. (2011) directly refered to social role literature and provided, in addition to a synthesis of Harrer et al. (2008); Halatchliyski et al. (2010); Iba et al. (2010), a complementary perspective of Huriva's classification, integrating the social interactions (the discussion activities). They looked for "structural signatures social attributes of actors", i.e. the actions taken, but also the network of interaction, and the social interaction, especially in the talk pages, in the user pages, and in the user talk namespaces. It is a rather exploratory survey, based on qualitative analysis for identifying roles, and studying the differences in action, network, social interaction of these roles using dump data. It does not provide a lot of extra information about the first four type of contributors, beside the fact that they pointed out that some of these contributors, they named "substantive experts", "invest time in fact checking and article talk to discuss details of articles" (p. 4). But their work seems to indicate that Huriva's "editors" can be split into three sub-groups, "technical editors", "make numerous small changes to content pages, frequently specializing in a particular type of problem" and with few presence in the talk pages (p. 7), "counter vandalism 
Tab. 1: Groups of Wikipedia contributors according to a qualitative analysis of the research data, from Huvila (2010), table 1.

\begin{tabular}{|c|c|}
\hline Group & Description \\
\hline Investigators & $\begin{array}{c}\text { Contributions relate to personal interest or hobby related area (of expertise) based mostly } \\
\text { on news sources, popular scientific or fact literature and/or visiting the local library [...] } \\
\text { They represent the hard core of contributors who start articles and make considerable } \\
\text { contributions to existing ones. } \\
\text { Members of the group were mostly graduates, professionals working on topics other than } \\
\text { those to which they are contributing. }\end{array}$ \\
\hline Surfers & $\begin{array}{l}\text { Contributions are based on easily findable sources available on the net. Surfers spend their } \\
\text { time on using search engines and finding fitting material for articles. Their personal } \\
\text { interest on the topics they are editing is similar to the group of investigators, but they do } \\
\text { not investigate the same sources of information. } \\
\text { Surfers are primarily secondary school educated, undergraduates and professionals. }\end{array}$ \\
\hline Worldly-wise & $\begin{array}{l}\text { These contributors tend to focus on topics relating to their own sphere of experience and } \\
\text { knowledge. They do not tend to seek information explicitly for their Wikipedia } \\
\text { contributions and tend to rely on serendipitous information seeking and information } \\
\text { discovery. } \\
\text { Background and the level of experience vary. }\end{array}$ \\
\hline Scholars & $\begin{array}{l}\text { Contributions on an academic or professional area of expertise. } \\
\text { The archetypal contributor in this small, but quite distinct, group is a PhD student or a } \\
\text { relatively young researcher who is contributing on the topics related to their research. }\end{array}$ \\
\hline Editors & $\begin{array}{l}\text { Some of the editors focus on administrative tasks, grammatical corrections, correction of } \\
\text { inconsistencies between articles, and another group on translations from other language } \\
\text { versions of Wikipedia. They do not generally seek information for their Wikipedia edits. } \\
\text { The group was very small and rather heterogeneous in the present study, but they shared, } \\
\text { broadly speaking, a professional background and a college level education. }\end{array}$ \\
\hline
\end{tabular}


editors" (ibid) who correct vandalized pages and post warnings in vandal's user pages, and the "social networking editors" (ibid), who invest few in the editing, but a lot in the social interactions, the community building.

Of course, as the motivations vary, the level or type of contribution may also vary among time. However, Panciera et al. (2009), using internal data of the English Wikipedia, with time series, and Dejean and Jullien (2012), surveying French Wikipedia contributors reached the same conclusion: the level of participation strongly depends on the first contributions to the project. Antin et al. (2012) went a bit further, showing that not only the level of activity, but also the type of tasks can be statistically predicted by the first contributions. But this does not mean that everybody follows the same path. For instance, Okoli and Oh (2007), looking at English Wikipedia contributors, showed that people having lots of participation in various articles (they assimilate to "weak links", in a Granovetter (1985)'s framework) are more likely to become administrator (to have administrative rights) than those more focused on a sub-set of articles and talking with a small subset of people (and then developing strong(er) links). In addition to this, it seems that the administrators are not among the most active contributors to the articles, and that their share in the total contributions is decreasing over time, at least for the English Wikipedia (Ortega and Gonzalez Barahona, 2007). This lead Zhu et al. (2011), relying on Bryant et al. (2005)'s study, to propose two main careers for the people, coherent with Okoli et Oh's findings: from non-administrators to administrators and from non-members to Wikiproject regular members to Wikiproject core members (figure 1, page 3433). On that aspect, Antin et al. (2012) confirmed that people involved from the beginning in more diverse revision activities are more likely to take administrative responsibilities.

These findings reinforce the perception that there is an à la Becker career for contributors, and different paths of participation, with a learning process (future contributors are firstly readers "dipping their toes in to passively participate while learning more about a complex system", according to Antin and Cheshire (2010), surveying a population of US college students). As it is the case for the involvement in other communities of practice like open source (see, for instance, Fang and Neufeld (2009) and Schilling et al. (2012)) there is a period of apprenticeship, via legitimate peripheral participation (Lave and Wenger, 1991), as showed by Bryant et al. (2005). 
These last paragraphs question the existence of an "efficient" structure of interaction to produce the articles and of an "efficient" process of inclusion. But before looking at these interactions, we have to better understand what is produced, the pieces of knowledge that are the articles and the articulation between them.

\subsection{Pieces of knowledge, articles, and global structure.}

Being the core of the project, it is not surprising that this topic is one of the first to have been studied. The studies can be split in two, the firsts looking at the articles in general, the seconds studying one specific kind of articles, the Feature Articles, which are considered by the projects as the best articles (their intrinsic quality is, however discussed (Lindsey, 2010), and the arguments of quality to qualify an article as Feature Article (FA) varies from one language to another, according to Stvilia et al. (2009), two points we will come back to in the last section). As for the precedent sub-section, we will start from the studies looking at the global structure of the project (and relying on statistical analyses of the dump data, for most of them), toward the analyses of the edition of article, finishing with some remarks on the dynamics of interaction behind this process.

\subsubsection{Structure of the project.}

Voss (2005) provided with the first global figures on the articles (mostly on the German Wikipedia), showing a lognormal-like distribution in their size (ibid, Figure 3, p. 6), which stabilizes when the project gets a certain size (even if the articles' mean size is growing) and that the number of distinct authors per article follows a power law (Figure 4, p. 7), as the numbers of ingoing and outgoing links (ibid, Figure 7, p. 9). Nazir and Takeda (2008) found globally the same results on the English Wikipedia for the number of users per article. Capocci et al. (2006) looked at the links between articles and found that the structure of these links is closed to the World Wide Web's one and found "a scale-invariant distribution of the in and out degree". This led them to conclude that "Wikipedia growth can be described by local rules such as the preferential attachment mechanism ${ }^{21}$,

\footnotetext{
${ }^{21}$ From Barabási and Albert (1999), this mechanism says that the more popular articles (in terms of contributors, links...) are, the more likely to increase their popularity is.
} 
though users, who are responsible of its evolution, can act globally on the network." Note that this preferential attachment mechanism has been proposed as an explanation by Voss (2005, p. 9). These considerations have been summarized by Wang et al. (2009), saying that a small number of people is strongly connected to lots of people and assures the coherence and the small world effect of the model, whereas the vast majority aggregates around centers of interests and is poorly connected. Also, the more popular topics (and central people) are those who aggregate new people the more (Keegan et al., 2012 gave an example of this phenomenon: looking at articles about plane accidents, they showed that breaking news articles are those which are the most likely to attract new editors, when experienced users remained more focus on their own agenda and editing 'their' set of article).

Zlatić et al. (2006) did similar analyses on the main Wikipedia languages projects and found that "degree distributions, growth, topology, reciprocity, clustering, assortativity, path lengths" are common, and defended the idea of an unique growth process. Finally, Wang et al. (2010), studying the categories (or tags) which define the pages, showed that there is an obsolescence phenomenon, as if the categories followed the actuality or that they are created when the articles and the topics they refer to are created.

One has to be very careful, however, to draw general conclusions from the analysis of the global structure of the project. As shown by Silva et al. (2011), who analyzed four sub-projects of the English Wikipedia (Biology, Mathematics, Physics and Medicine). These sub-projects present very different structures regarding the links between articles, with dense links in biology and medicine and less in physics and Mathematics. The reasons for these differences are not explicit, and more work would be useful to understand if they are due to the internal characteristics of the disciplines or to the internal organization of the Wikipedia sub-projects. (We will come back to this point in the discussion on the growth of the project at the end of this part).

We have not found any comparison with the other online encyclopedias regarding the global structure (distribution of the size and of the links of an article), a study which would be interesting to conduct to see if Wikipedia is different on this aspect. 


\subsubsection{Structure of articles edition.}

Gorgeon and Swanson (2009) studied one single article (Web 2.0), an article edited by more than 1,000 different people, and showed that the publication followed an S-curve pattern. Taking an actor network theory perspective (Latour, 2005; Akrich et al., 2006), Swarts (2009) showed how the building of an article, especially a polemic article (clean coal), is a process of accumulation of facts, and of "translation" of arguments or proposals in facts, this accumulation of facts being harder and harder to contest and thus to delete. It is partially confirmed by Luyt et al. (2008), who showed that "a sizable number of error edits occurs in the very first edit" and if "many more error edits appear in the last third [part of the life of the article], a fifth of the errors [remaining] are attributable to the first error edit." As early as 2004, Viégas et al. (2004) also found that, in the English Wikipedia, there is a strong dependence on the first edit for the global structure of the article. Finally, Halfaker et al. (2009) showed that "the number of reviews a word survives is a strong predictor of whether the edit that removes the word will be reverted" (p. 9). The question these articles raise is how the negotiation around the facts is done, and what the structure of the team needed to do it is, things we are going to analyze in the next sub-section.

Another important part of the literature looks at the characteristics of the articles, and particularly of the articles recognized by the producers as good (the Featured Articles, or FA). Luyt et al. (2008) proposed a still actually categorization of the different algorithms used to automatically retrieve the Feature Articles.

For instance, Lih (2004); Brändle (2005); Wilkinson and Huberman (2007), confirmed by Ortega (2009), found that after taking into account age and visibility (using Pagerank as a proxy), those Featured Articles have statistically more edits and editors. Wöhner and Peters (2009) refined these analyses, showing that these articles are "in general more persistently edited than low quality articles and that on the other side they have a stage of a high editing intensity in their lifecycles". (p. 7)

Adler et al. (2008a), on the English Wikipedia, noted that "incorporating the authority of reviewers gives good and robust performance" to characterize FA articles. This authority is measured 
as evaluating author's contributions life-length, based on the argument, brought by Cross (2006), that their persistence is a proof a quality (something which is quite fragile, Luyt et al., 2008 showed). Hu et al. (2007) on a subset of articles, found the same result. Mcguinness et al. (2006), based on the same idea as Pagerank, looked at the internal links pointing to the articles (they named the "trust ratio") showed that Feature Article are significantly more cited.

Also, and coherent with the analyses done on the contributors, FA articles have experienced editors participating to their redaction (Stein and Hess, 2007). More precisely, a fine tune of experimented editors and fresh newcomers increases the likelihood for an article to become FA (Ransbotham and Kane, 2011), which, in other contexts, have been proven to be very important for group's creativity and efficiency (for instance, Uzzi and Spiro, 2005; Uzzi, 2008). Wilkinson and Huberman (2007) also found that these articles have more discussions on their talk page, which is rather normal as, as pointed by Arazy and Nov (2010), "processes for becoming a featured article explicitly require additional coordination activities" (p. 234).

But it seems that, in a first approach, the best indicators of an Feature Article, at least for the English version (Dalip et al., 2009) are the length and basic quality of the writing, as it is for open source contribution, actually ${ }^{22}$ : textual features related to length (result already stressed by Blumenstock, 2008), structure and style (Lipka and Stein (2010) even obtained a better result on FA identification with a machine learning approach on article styles than Blumenstock's algorithm on length); and those which count for the less, are the most complex features, such as those based on link analysis.

This kind of analysis can also be done at portal, or subject level, as did Poderi (2009), with rather against-intuitive results, as it seems from this analysis that subjects having more feature articles (high density subjects in his terminology) have longer articles, but less edit and contributors than low density subjects, while the ratio between major and minor edits is the same in the two groups. It seems also that there is more often a single major editor in the high density subject articles. However, as stressed by the author, this study has been done on a small subset of articles and should be extended to confirm its results. Jones (2008) proposed an analysis of the revision

\footnotetext{
${ }^{22}$ Hofmann and Riehle (2009) found that for open-source, simple heuristics are superior to the more complex text-analysis-based algorithms to estimate the size and the importance of a commit in open-source projects.
} 
patterns of the articles applying for FA label, and showed that the final structure of the article is very dependent on the first one, editors tending to expend sentences, paragraphs and sections. His study having been done on a small subset of the articles also (10), he questioned the fact this unique revision pattern is global or not, which seems to be the case, according to the studies done on the whole set of articles.

Iba et al. (2010) proposed an explanation to these seemingly contradictory results. According to them, there would be two types of FA (in the English Wikipedia): (1) articles of narrow focus created by few subject experts, and (2) articles about a broad topic created by thousands of interested incidental editors. Considering the preferential attachment mechanism, this phenomenon is selfmaintaining as the more exposed articles are, the more probable is the fact that people contribute to them (a result studied by Ransbotham et al., 2012).

\subsection{The organization, structure, and governance of the project.}

Kittur and Kraut (2008, p. 18) noted that "decades of research in organizations show that communication as the basis for coordination is especially important in tasks that are highly uncertain, unconstrained, and subject to many changes", as can be the construction of the content of an article (Cardon and Levrel (2009); Cardon (2012) explained, in the particular case of Wikipedia, why and how the rules in use are not always enough). This explains the importance of the talk pages in the project, even if there are variations between the projects (Voss, 2005 showed strong differences in the ration: user talk over user pages, between the European projects (German 0.94, Danish 0.88, Croatian 0.74) and the Japanese one, 2.51). Panciera et al. (2009), quoting Viégas et al.'s result that over half of Talk page comments are requests for coordination and $8 \%$ are policy invocations (2007), concluded that Wikipedia contains strong and supportive communities. Butler et al. (2008) also found that much of the explicit coordination is managed through the Talk or discussion pages for the article in question.

Not surprisingly, if taking into account Actor Network Theory (Latour, 2005; Akrich et al., 2006), studying these discussions, and especially the "conflicts", can give explanations on the repartition of the work between direct contribution to articles, vandalism fighting and discussion or negotiation 
of the "point of view", leading to mutual adjustments when the rules are not enough to do so, but also of the brutal rejection of "pathologic" discussants (Auray et al., 2009). It is also a well know issue for distant (virtual) organizations (Hinds and Bailey, 2003; Hinds and Mortensen, 2005), both negative because it consumes people's time, and positive because it can strengthen the community $\left(\right.$ Franco et al., 1995) ${ }^{23}$. We have not found survey on the patterns of interaction, probably because they will suffer from the same problem as the ones regarding implication, and because of the already rich data available. These surveys would be of help, however, to understand how people choose the article they contribute to (topics, people working on it), and their perception of the conflicts, and thus to deeper the understanding of the structure of interaction the data analyses make apparent.

But before looking, thanks to the discussion pages (and the analyses made on them), at the processes behind the life of an article (creation, deletion, evolution, promotion), and at the managerial behaviors, and to follow up the discussion started, we will start giving some results on the who and the how of the construction of an article. In a word, what a 'good' team to construct an article is.

\subsubsection{People, team and articles.}

People and articles. Halfaker et al. (2009) found "strong evidence of ownership behaviors in practice" in the production of an article, especially in the articles designed as "Maintained", according to Thom-Santelli et al. (2009), despite the fact that ownership of content is discouraged. And, even if less geographically situated than Flickr contributors (Hecht and Gergle, 2010b), Wikipedia ones can often be associated with "relatively small geographic regions, usually corresponding to where those users were born or where they presently live. Also, for many users, the geographic coordinates of pages to which they contribute are tightly clustered" (Lieberman and Lin, 2009). Finally, Hardy et al. (2012) geolocalized IP addresses for the anonymous contributions to geotag articles in 21 language projects and concluded that "the likelihood of an anonymous contribution to a geotagged Wikipedia article exponentially decreases as the distance between the contributor and

\footnotetext{
${ }^{23}$ For a discussion of the cause of conflict, the way the Wikipedia organization could avoid them and the need for a better understanding of the process of conflict management, see the study of "the bibliography of the living persons in Wikipedia" by Joyce et al. (2011).
} 
article locations increases". All these behaviors are coherent with the findings of Zhang et al. (2010) who concluded that it seems that people involve themselves on a very specific themes, at article level, rather, than, for, instance at domain level, after looking at a subset of articles on terrorism and comparing them to the Terrorism Knowledge Base. As pointed by Thom-Santelli et al. (2009), this focus, these ownership behaviors, are not bad per se, especially in the first stages of an article where a small team seems to be more efficient. But it can lead to overprotection and can decrease the final quality of an article (see bellow the discussion on the form of the team).

This does not mean either that there is no coordination at project level or that people can not be asked to joint a particular project. On the contrary, Zhu et al. (2011) showed how the personal pages are specifically used to do so. But this must be fine tuned: Choi et al. (2010), also analyzing the messages on the personal pages, showed that welcome messages, assistance written in newcomers' pages are quite effective to improve their contribution, when "invitations led to steeper declines in edits." Other actions can also attract contributors and structure the teams or, more precisely the discussions, such as template message on the articles: Rossi et al. (2010) studied the role played by NPoV (neutral Policy Violation) templates, which if not made completely explicit by their analysis, seem to be used to settle evidence of a latent conflict (Den Besten et al., 2010), and thus to attract the attention of the community on a problem which has to be solved, whereas other template messages seem to be more treated as simple messages.

These recruiting actions play a crucial role in the construction of a "good team" for writing an article, which appears to be a congregation of experienced people having already work together with new talents.

Form of the team. Kittur and Kraut (2008) showed that explicit coordination (talk) is more efficient when there are few editors, when implicit coordination (few editors editors concentrate the main part of the edits when the majority is peripheral editor) is more efficient when there are more editors. They also found that explicit coordination is needed more at the early stage of the article. In any case, there is a core-periphery structure, similar to the one found in open source software production, and things are easier when the core team people already know each others: Nemoto et al. 
(2011) pointed out that "the more cohesive and more centralized the collaboration network, and the more network members were already collaborating before starting to work together on an article, the faster the article they work on will be promoted or feature". In the same time, Chen et al. (2010), evaluating diversity according to an evaluation of the interest of the persons via their contribution, showed that "increased diversity in experience with Wikipedia increases group productivity and decreases member withdrawal - up to a point. Beyond that point, group productivity remains high, but members are more likely to withdraw". Interestingly for this theory, Turek et al. (2010, p. 22) showed, using Polish Wikipedia data set, that in what they call "good teams", the level of acquaintance is higher than for normal teams (people having discussed in the talk pages) as is the level of trust (copy-pasting of existing text when rewriting an article) and of distrust (deletion of text), which can be seen as the level of creative work (if people delete more that means that the consensus is reached more slowly, after more evaluation of the proposals). This is true for FA, but also when articles' quality is measured by external experts, as in Arazy and Nov's article (2010), who estimated the impact of local inequality and global inequality on the quality of the article: having a small team, very committed (strong local inequality), improves the coordination (and thus indirectly the quality), and having strong global inequality (people very invested in Wikipedia and peripheral contributors) improves the quality of the articles (of course, this work may be extended to a bigger set of article to be confirmed). Gómez et al. (2011) also showed that "once a comment on a Wikipedia article has been originated, it will derive in a collaborative reciprocal chain between a very reduced group of contributors", indicating, and contrary to the contribution to an article, an "inverse preferential attachment process" for the discussions (p. 8). Finally, Xu et al. (2008) can be seen as a summary of these findings: using an agent simulation, they retrieved these results, showing that more agents improve the convergence and the quality of the article, especially if they are more knowledgeable, and vandalism, if increasing the number of updates, does not stop an article from being improved (it can be seen as test which allows to question the team and eventually improves its production). 
Conclusion. The conclusion can be led to Arazy et al. (2011), even if they focused only on a very small subset of articles (96): "(1) diversity should be encouraged, as the creative abrasion that is generated when cognitively diverse members engage in task-related conflict leads to higher-quality articles"; (we will just add "up to a point" here) "(2) task conflict should be managed, as conflict notwithstanding its contribution to creative abrasion can negatively affect group output" (we will come back to this point in the next paragraph); and "(3) groups should maintain a balance of both administrative- and content-oriented members, as both contribute to the collaborative process."

This echoes more general findings about the efficiency of groups. As shown by Uzzi and Spiro (2005) in the case of musical comedies, and Uzzi (2008) in the case of a social network, for a creative group to be successful, it needs to fine tune the level of newcomers, for fresh ideas, in an already constituted group (for trust and common sharing, or "cohesion", especially on what a good article is for Wikipedia, as, according to Arazy and Nov (2010), the fact to have people having experience in the contribution in general, or, as we named them before, boundary spanners, is even more important than to have people who involve themselves in the production of the article). Wikipedia seems to be another proof of this principle and it would be interesting to calculate Wikipedia's "Q"-level "bliss point".

This Q-level may depend on the type of article, more specialized, "narrow focused", or more general: Keegan et al. (2012), comparing breaking news with historical articles on the commercial airline disasters, in addition to find the same results as the articles already cited about the link between quality and number of editors or length of the article, showed that breaking news articles are more often chosen by newbies, and that experienced users may avoid this kind of article.

These studies on the structure help to understand what is needed to make an article, but give few information on the making, of the life of this article, and on the interactions needed for this making, which is the subject of the following paragraph.

\subsubsection{The life of an article: creation and deletion, redaction, and promotion.}

We will start with two main moments in an article life, the decisions of deletion and of promotion, before looking at a larger-in-time process, the cooperation around the article. 
The decisions regarding an article. The editing arguments leading to these deletions are quite on line with the rules of the project, as shown by West and Lee (2011), on a corpus of one year deletions in the English Wikipedia: the non-respect of the non-novelty rule, but also, the ones which "present a legal liability to the host (e.g., copyright issues, defamation), the harder to detect, or privacy threats to individuals (i.e., contact information)." If copyright issues are hard to discuss, the others are subject to interpretation and the decision of deletion can be taken after a vote. On that aspect, Taraborelli and Ciampaglia (2010) showed that there is a "herd effect": "an over- or under-expression of preferences in the initial part results in an over- or under-expression in the following" (p. 3), which, according to the authors, can be due to recruitment activities among voters' group, or as studied by Geiger and Ford (2011) on the English Wikipedia, that the final decision remains to experimented users, and that this expertise is recognized by the voters. Lam et al. (2010) analyzed the various elements impacting the quality of the deleting decision and we reproduce their findings in table 2 , page 34 .

This mechanism is also apparent in the process of promotion of the articles. Keegan and Gergle (2010), who studied a corpus of 161 deliberations (in a 3 month time frame), concluded that elite users "fulfill a unique gatekeeping role that permits them to leverage their community position to block the promotion of inappropriate items. However, these elite users are unable to promote their supported news items more effectively than other types of editors." (on breaking news stories)

Conflict during the reaction of the articles. As Goldspink et al. (2010) showed, the appeal to the rules is rare in the discussion, in mean, but more important in the controversial articles, as "behavior seems to accord to a convention which editors quickly recognize and conform to (or bring to the Wikipedia) and which minimally accommodates what needs to be done to satisfy the task in a context of divergent personal goals". However, as pointed by Black et al. (2011), who analyzed discussions and deliberation in small groups (based on the deliberative discussion theory they developed in Gastil and Black (2008)), if the discussion groups present a "relatively high level of problem analysis and providing of information", the "results were mixed in the group's demonstration of respect, consideration, and mutual comprehension". An hypothesis which has to 
Tab. 2: Impact of the structure of the group on the quality of the decision regarding article deletion, from Lam et al. (2010), table 3, p. 10.

\begin{tabular}{|c|c|c|}
\hline Hypothesis & Result & Description \\
\hline \hline H1 Bigger-Better & Supported & $\begin{array}{c}\text { Larger groups make better decisions, but with } \\
\text { diminishing returns }\end{array}$ \\
\hline H2 Recruit-Worse & Mixed & $\begin{array}{c}\text { Biased recruitment leads to worse decisions under } \\
\text { some circumstances }\end{array}$ \\
\hline H3a Newcomers-Worse & Supported & $\begin{array}{c}\text { Newcomer participation yields worse decision } \\
\text { quality }\end{array}$ \\
\hline H3b Diversity-Moderate & Mixed & $\begin{array}{c}\text { Diverse groups may make better decisions; no social } \\
\text { categorization effects were observed }\end{array}$ \\
\hline H4 Biased-Admin-Worse & Supported & $\begin{array}{c}\text { Worse decisions in some cases if decision agrees } \\
\text { with administrator's bias } \\
\text { Better decisions in some cases if decision is contrary } \\
\text { to administrator's bias }\end{array}$ \\
\hline
\end{tabular}

be tested is that the appeal to the rules is thus used only in the extreme cases when the conflict cannot be solved, when personalities are involved, or when points of views refer to different level of legitimacy.

Looking at the discussion pages and at the disputes allows to go deeper in the discussion process around the creation of articles (see the in-depth analysis of the conflicts in the French Wikipedia by Auray et al. 2009), but also to discuss this hypothesis. The analysis of the conflict by Kriplean et al. (2007) showed that if the appeal to the policies (the rules) is the main tool to resolve conflict, "ambiguities in policies give rise to power plays" (how groups of contributors claim legitimate control over content through the discourse of policy) ${ }^{24}$, and Nagar (2012) explained that the questionanswer structure forced by the wiki environment, and especially the talk pages, "amplifies the publicity and irrevocableness of volitional interacts, and thus intensifies the process of turning them to commitments" (p. 400), facilitating the convergence.

Going deeper in the characteristics of the interaction and of the sense building, Fréard et al. (2010) used a social role analysis ${ }^{25}$ to study how different contributors participate to the construc-

\footnotetext{
${ }^{24}$ Even if Wikipedia has a rule, or a guide, about dispute resolution, see http://en.wikipedia.org/wiki/ Wikipedia:Dispute_resolution.

25 They relied on manual analysis of the conflict, but also on a tool which automates these study via natural language analysis (in French). This method, quite promising, may lead to new characterization of the articles, in terms of level of conflict and of data produced, and could complete Fong and Biuk-Aghai (2010)'s and Viégas et al. (2004)'s works, in addition to Kittur et al.'s mechanism to detect conflicts (p. 6, the most important input, according
} 
tion of an article taken as collective output, here on the conflict on Pluto article discussion page (is or is not Pluto a planet?) They spotlight the debate/conflict between academic knowledge (Pluto is not a planet because it has been defined as not being a planet) and Wikipedia structure (people will look for Pluto as a planet and they have to find it like that, even if later the article tells them they are wrong), which can lead to personal conflict. It is interesting to note that when personal conflict happens, the discussion and the reverts may discourage people to participate to the article, as, as shown by Kittur et al. (2007b), "the number of unique editors involved in an article negatively correlates with conflict to be read" (p. 6). It would be interesting to extend these studies looking at the relative status of the persons involved in the conflict to see if, more than a formal position, people look at relative position to accept or refuse each other proposals, as recent works in social networks indicated (Burt, 2009; Leskovec et al., 2010b).

When these conflicts are unsolvable, they can lead to the exclusion of a participant, or to the move of the conflict to another space (appeal to a mediator, or, as Billings and Watts (2010) called them, a "conciliator", moving of the dispute in the conciliation section of the site, where disputants are isolated from the others with the moderator). This provides the organization with multi-levels way of coping with conflicts, before reaching the extreme measure of blocking this conflict, at article level (freezing an article) or at individual level (excluding a person). In both cases, a managerial decision is taken, decision we are looking at in the next paragraph.

\subsubsection{Management and leadership.}

One of the most important task for the leaders or the animators of virtual communities is to involve people and to keep them involved, according to the literature on virtual management (see Crowston et al., 2010, p. 15). According to Zhu et al. (2012), in Wikipedia too, leadership behaviors matter to motivate people to participate, especially when "transactional leadership and person-focused leadership" are used. Illustrating this point, Billings and Watts (2010) showed that thanks to the wiki tool which allows citations, conciliators solve disputes by helping differentiate "the personal and substantive" (p. 6) in close interaction with the disputants, and Musicant et al. (2011) found to their model, is the number of revision). 
"significant correlations between editor communication and article editing activity" (but without being able to evaluate the direction of the correlation).

This, however, seems to be insufficient to avoid the difficulties the projects meet to keep the contributors we mentioned in the introduction. Halfaker et al. (2009) found that "as they gain experience, contributors are even more likely to have their work rejected". As they explained (p. 7), referring to Bryant et al. (2005), this may be due to the fact that "editors [are] being more bold as they gain experience", and Halfaker et al. (2011) found a positive impact of the revert on the quality of the production. But they also showed that the revert effect is particularly discouraging and excluding for newcomers. The authors plead for a better communication toward these newcomers specifically and the reverted in general, but the ones who are involving in a discussion are more likely to stay and to produce work of better quality. And Musicant et al.'s analysis of the Wikipedia programs "adopt a user" (for the English Wikipedia) and "Mentorenprogramm" (for the German one) exhibited mitigate success, as "communications specifically between adopters and adoptees do not seem to offer advantages over other forms of editor communication" (2011, p. 9).

These meta-analyses, as the analyses on the production of an article we presented before, show that the lens should be focused on a closer-interaction management, at group and article level, where the day-to-day management is conducted (Forte et al., 2009). As Forte et al. (2012, table 1, p. 2) pointed out, relying on McGrath's typology of (small) group modes and functions (1991), this is exactly what these nested organizations are made for, in addition to production activities support: maintaining group's well being and providing support to members. Using the concept of Legitimate Peripheral Participation, proposed by Lave and Wenger (1991), in the case of Wikipedia, Bryant et al. (2005) showed that the technical structure of the project also facilitates newcomers' slow involvement (they showed how the interface help to choose the task to do, or how the article can be improved, which is also done at project level). Choi et al. (2010), in their examination of Wiki Projects showed positive impact of welcome messages, assistance, and constructive criticism on newcomers' edit levels. This finding is also consistent with Musicant et al.'s recommendation to improve the mentoring program by better matching mentor and adoptees on their field of interest, to improve the "empowerment mechanisms" (Hansen et al., 2009) of this project. 
Two levels of leadership would then exist in Wikipedia. A project leadership, focused on content, where discussion and coordination are very linked to contribution at article level (Ung and Dalle, 2010), with strong socialization effects (Forte et al., 2012), and a more global management, aiming at solving the cases unsolved (in that respect, Zhu et al., 2012 showed that what they called the "legitimate leaders", or leaders having official responsibilities are more likely to be followed). Here again, an analysis of people's comparison of relative status (Burt, 2009; Leskovec et al., 2010b) may shed light on the process of interaction.

This two level of management is well illustrated by Zhu et al.'s study (2011) on the differences between administrative persons ("admin" or "sysop") and project leaders, in the English Wikipedia. They developed a tool making possible to automatically assess the kind of message sent (positive, negative, directive or social). If there is no significant differences in the volume of messages posted by these two types of leaders, they showed that local project leaders leave more task oriented messages when administrators are more in the social exchange, sending more personal messages (p. 4). This may explain the difficulties for retaining newcomers, as the project leaders would be too directive and not socializing enough. It can also prove that the administrators intervene when people's behavior become a threat to the well-being of the global project. But this study was done on the personal pages' messages, thus on the most involved people's exchanges, and skipped the project articles pages, where more social exchanges may occur. So, as the authors acknowledged, if it gives additional proves of the existence of those two levels of leadership, it must be completed.

The admin election process gives insights of how these two levels articulate. Ortega and Gonzalez Barahona (2007) showed that the admins are not the ones who contribute the more to the articles, and Burke and Kraut (2008) extended this point showing that the candidate's article edits were weak predictors of success: they have to demonstrate also managerial behaviors. Diverse experiences and contributions to the development of policies and to WikiProjects are stronger predictors of RfA [Request for Adminship] success. Future admins also use article talk pages and comments for coordination and negotiation more often than unsuccessful nominees, and tend to escalate disputes less often. In addition to this, Leskovec et al. (2010a) showed that the voters favor people who have the same characteristics than them, i.e. who are on comparable or superior merit (and vote 
negatively for those who are of lower merit, Leskovec et al. 2010b), especially when these people are in minority. Cabunducan et al. (2011) showed that "voters tend to participate in elections that their contacts have participated in" and that "candidates who gain the support of an influential coalition tend to succeed in elections".

To be exhaustive, a third level of leadership should be considered, the Wikimedia foundation, and the process of election of the members designed by the participants, studied. But the results already found are consistent with the theoretical study made on leadership in self-managing virtual teams by Crowston et al. (2010), and based on leadership theory and structuralism theory. According to these authors, in these communities, there would be a "first-order leadership [...] that works within and reinforces existing structures to elicit and guide group contributions" and a "secondorder leadership as behavior that effects changes in the structure that guides group action [...] enabled by first-order leadership, therefore action embedded, and grounded in processes that define the social identity of the team. [...] effective self-managing virtual teams will exhibit a paradoxical combination of shared, distributed first-order leadership complemented by strong, concentrated, and centralized second-order leadership [...]" (pp. 28-29).

Finally, this organization, and the evolution of the participants from personal interest regarding the contribution toward collective interest, but also the importance of the discussion about the building of trust to become a regular contributor, echo reflexions on management, especially stewardship practices (Davis et al., 1997), and the alignment of people's interest and collective's interest (Hernandez, 2012). This leads us to a more general conclusion on the process.

\subsubsection{Organization, process, a conclusion.}

Otto and Simon (2008) proposed a global model to estimate the evolution of Wikipedia participants and to evaluate the impact of management on people's willing to participate, and on the production, which can be seen as a metaphor of the findings presented in this section. They used Douglas' grid/group framework $(1970 ; 1978)$, where people's behavior is more or less constraint by their commitment to the group (high/low) and by the structure of the organization (high/low). Their model shows that "while an open environment accelerates the growth of an online network at 
the early stage, openness may negatively impact quality and subsequently the attractiveness of the network, so that users will be less inclined to join or to participate in the network" (p. 346). Actually, this seems to be true at each level of the project (the global language project, the thematic projects and the articles).

Wikipedia would be a new system controlled by an oligarchy based on expertise (Hansen et al. (2009); Hartelius (2010), extended by Pfister, 2011), creating, according to Konieczny (2009a; 2010), and his detail discussion of the model of governance in Wikipedia, a Mintzberg's model of adhocracy (2007), "one closely connected to open-source development models found in the FOSS movement". Editors at Wikipedia would "share the adhocratic values of flat hierarchy, decentralization, little managerial control, and ad-hoc creation of informal multidisciplinary teams. Like individuals throughout most of the FOSS movement, they are highly motivated - not by potential financial gain, but by their project's ideology" (Konieczny, 2010, p. 277) (but also, we add, by the social connexions, and the social and knowledge rewards the participation provides). However, if, according to him, "in traditional adhocracies, individuals are bound by rules that cannot be altered; at Wikipedia, by contrast, there is no rule that cannot be altered if the community so desires", beside the main iron rules (the five pillars), seemingly. In addition to that, "in Wikipedia's adhocracy, the editors not only "capture opportunities," but they also can create those opportunities, since editors can change all policies and so enjoy an unprecedented degree of empowerment" (something stressed by Hansen et al., 2009; Hartelius, 2010; Pfister, 2011). More studies should be pursued to see if this model is a new implementation of the global adhocracy model or if falls in the model proposed by Mintzberg and McHugh (1985).

\section{Evaluation, points of view.}

As explained by Hammwöhner (2007, p. 3), Wikipedia quality can be assessed either via internal measures (Wikipedia has several levels of quality for its articles, from article needing to be improved to featured article, see http://en.Wikipedia.org/wiki/Wikipedia: Article_development), as in Poderi (2009); Carillo and Okoli (2011); either by external metrics coming from both the information 
system studies on the quality of the process, on the information system (Stvilia et al., 2008, Wöhner and Peters, 2009), and the bibliography studies (on the product); or subjectives metrics (user experience, being reader or producer). As pointed out by Lewandowski and Spree (2011, p. 6-7), referring to Geeb (1998), the evaluation of the quality of a work can not be done independently from the definition of the user: "degree of expertise such as layperson or expert, user situation referring to the actual usage such as text production or understanding, and user intention, which can widely vary from gathering factual information to background information or references". And, in a way, as Wikipedia addresses both specialists and novices, learners and information checkers, an analysis should be done for each of these users and uses. However, some indicators exist to evaluate the quality of an article, or the coverage of a project, and these indicators have been used for Wikipedia too. Considering this, and following the main parts of Lewandowski and Spree (2011), not in the same order, we will look at the quality of the process, the user experience and the external evaluations of the quality of Wikpedia's entries (articles) and coverage.

\subsection{Process Quality and Efficiency.}

Some partial analyses proved the reactivity of the (English) project, especially to cope with damages, because most of the articles are regularly edited: Buriol et al. (2006) indicated, for instance, that over $80 \%$ of the articles were updated in a three-months period. Thanks to this constant vigilance, Viégas et al. (2007a) showed that "mass deletions were reverted in a median time of 2.8 minutes, and obscene mass deletions were reverted in a median time of 1.7 minutes" (p. 4). Priedhorsky et al. (2007) confirmed this speed, as they found that $42 \%$ of damage incidents are repaired almost immediately (i.e., within one estimated view, i.e. one person looking at it). However, they also found that " $11 \%$ of incidents persist beyond 100 views", but only "0.75 - beyond 1000 views" (see figure 7 page 7 of their article). Going a step further, Halavais (2004) introduced errors in article, which were all removed within $48 \mathrm{~h}$. Magnus (2008) improved the process, making the group of errors less easy to detect, and noted also good reactivity. If these analyses prove Wikipedia organization's efficiency to preserve the existing stock of knowledge, they do not give information about the process to produce new stock. 
Suh et al. (2009) showed that "both the rate of page growth and editor growth has declined" in the English Wikipedia. As we viewed in this document, this is a strong indicator of growing coordination costs, with an increase of the structure of governance and of the discussions in the talk pages, at least for the main projects, several points indicating that some projects may be in the decreasing phase of the S-shape production curve. Crowston et al. (2013), using digital environment analyses tried to model the production curve, or more exactly to compare the efficiency of the different language projects, and confirmed that some of the main projects are less efficient, but without being able to make this a rule, especially when taking into account the quality of the articles (the FA). If these studies represent a first step toward evaluation the efficiency of this online community, this is one of the less explored field in Wikipedia studies.

One of the reasons for the few number of studies may be the difficulty to evaluate this quality, whose perception is socially constructed and constantly evolving (Stvilia et al., 2008, 2009), and the process behind, the information quality process as defined by these authors (Stvilia and Gasser, 2008). Stvilia et al. (2008) proposed an in-depth analysis of the rules, the structures, and the interaction behind the creation of Wikipedia articles, and especially the Feature Articles. They concluded that Wikipedia has, today "not only a set of formal quality assessment criteria, but also a whole infrastructure of quality evaluation and promotion mechanisms and guides" (p. 997), supported by a specific interplay between the technology and community mechanisms, which created "a new system of IQ assurance that is robust and that promotes continuous IQ improvement" (p. 999). For instance, the double level of management, but also the small group control of articles and projects help to understand how Wikipedia copes with producing articles of quality without identified authors, when (Miller, 2005), summarized by de Laat (2010), pointed the fact that the trust comes with a decrease of the anonymity. If the evaluation of the efficiency of this system in terms of productivity is still a work in progress, several studies exist on the evaluation of the stock of knowledge produced, and on the quality of the experience of its users. 


\subsection{Users' experience.}

\subsubsection{Developers' experience.}

The situations and purposes for which the editors use Wikipedia seem to be similar as for other users, according to Francke and Sundin's study (2010), based on the interviews of 11 Swedish Wikipedia editors. However, they draw on their knowledge as members of the network of practice of Wikipedians to make credibility assessments, including knowledge of certain editors and of the MediaWiki architecture. Their assessments have more similarities to those used in traditional media than to assessments springing from the wisdom of crowds. Thus being editors would give extra information on the encyclopedia and make it be used more efficiently.

Regarding the impact of the quality process on editors' motivation, Halfaker et al. (2011) showed that "that reverts are powerfully demotivating, but that their net influence is that more quality work is done in Wikipedia as a result of reverts than is lost by chasing editors away. However, [they] identify key conditions - most specifically new editors being reverted by much more experienced editors - under which reverts are particularly damaging." In addition to this, the process of decision is viewed as "bureaucratic" by the editors (Müller-Seitz and Reger, 2010). These two points can threaten the participation in the long run as there is a link between contributors' enjoyment and participation, as shown by Amichai-Hamburger et al. (2008). Lopes and Carriço (2008), doing an analysis of quality of the links, showed that the implementation of template for internal links improved the quality of these links, whereas this quality was not that good for external references. It would be interesting to study if the fact that there is an asymmetry between internal facility of use and external relationship management difficulties is a more general characteristic of the MediaWiki tool, and if improvements are needed or possible. More specific studies exist, such as Buzzi et al.'s on the way to improve the easiness of editing for the blind (2008), which showed that several problems remained in 2008 , some of them not yet solved ${ }^{26}$.

\footnotetext{
${ }^{26}$ See the page dedicated to this particular problem: http://blind.wikia.com/wiki/Mediawiki_and_ Accessibility
} 


\subsubsection{Readers' experience.}

System use. One of the obvious way to measure the users' interest for the encyclopedia is to measure the frequenting, in total or regarding the topics. Various tools to do so are available and presented on a dedicated Wikipedia page (http://en.wikipedia.org/wiki/Wikipedia:Statistics ). The Wikipedia Web site is ranked 6 in the world, according to Alexa ${ }^{27}$. The availability of these statistic tools may explain that there are few researches on the frequenting, or because, as pointed by Spoerri (2007a), despite all these tools, there is no will from the site to present the most visited article, like in Youtube or Digg ${ }^{28}$.

Spoerri (2007a, a, b), looked at the 100 most visited pages, and at their stability during several following months. He showed that the encyclopedia answers to two kind of researches, on the actuality (death, new films), which vary over time, and on major historical events (World War 2 , for instance), which are more stable. If the vast category "Entertainment" represents $43 \%$ of the articles in the top 100 (and sexuality 10\%), Politics and History (15\%), Geography (12\%) and Science $(6 \%)$ represent major categories for the visits. As pointed out by the author, Wikipedia is primarily accessed via the browsers and this list reflects the research on the Web for which Wikipedia is one site of reference, thus the actuality, but also some more stable interests among the people (as shown by the analysis by Ratkiewicz et al., 2010). In that aspect, Wikipedia can be seen as the encyclopedia of the everyday life, as had been the French Encyclopedia "Quid"29 during 40 years, before being killed by the online encyclopedias (Letessier, 2007). But it is also an encyclopedia of reference for researchers, integrated in their routines when dealing with peer-reviewed research report (Dooley, 2010). Finally, the confidence in the self capacity to evaluate the accuracy of the information is important in the users' experience, as shown by Lim and Kwon (2010) in their survey of undergraduate students. They also showed gender differences, such as the fact that males use more Wikipedia for entertainment and idle reading than females, and have better expectation and reward from using this tool.

Finally, and as already mentioned in the introduction, the evaluation of Wikipedia as a credible

\footnotetext{
${ }^{27} \mathrm{http}$ ://www. alexa.com/siteinfo/wikipedia.org+s ina.com. cn+orkut.com+live.com+youtube.com

$28 \mathrm{http}: / /$ www $\cdot$ youtube $. \mathrm{com} / \mathrm{browse}$ ? s=mp\&t=m\&c=0\&l= and http://digg. com/news $/ \mathrm{month}$

${ }^{29}$ http://fr.wikipedia.org/wiki/Quid
} 
source of information has been debated since its origin, in press, and in scientific articles. This leads today to a bias perception of its quality by the users (Flanagin and Metzger, 2011): "children rated information from Wikipedia to be less believable when they viewed it on Wikipedia's site than when that same information appeared on either Citizendium's site or on Encyclopædia Britannica's site". The analyses in terms of external measure or quality or in terms of user experience are more nuances on this aspect of quality. In his survey of 50 academics on Wikipedia articles in their area of expertise against articles outside it, Chesney (2006) showed that the experts (people who evaluate an article in their area of expertise) found it more accurate than people who evaluate an article outside their area of expertise.

Accessibility. A way to improve user experience is to improve, if possible, article accessibility, and the navigation in the site. Lopes and Carriço (2008) proposed a global model for evaluation accessibility to major websites, which have, such as Wikipedia, different types of users, aiming at accessing via different types of devices for different intentions, in different usage situation, but they did not do an analysis of Wikipedia. Some problems remain, summarized in the page dedicated to this point by the MediaWiki project ${ }^{30}$, but they do not seem to have attract a lot of researchers for the time being.

When an evaluation is done on the accessibility of the article, such as the one done by Mühlhauser and Oser (2008) on medical articles, it shows that these articles are viewed as less understandable than other sources (here major health insurance Web site), by the evaluators (med school students) but, as recognized by the authors, the study is very partial.

\subsection{Product quality.}

\subsubsection{Global coverage.}

The most obvious presentation of the product Wikipedia is by its number of articles, or the total number of pages (including redirection and discussion), available on the welcome page, and its size.

\footnotetext{
${ }^{30}$ See the page dedicated to this particular problem: http://blind.wikia.com/wiki/Mediawiki_and_ Accessibility
} 
The coverage is also available as internal data ${ }^{31}$, which reveals the structure of the encyclopedia, but also what is one of the basic rules of the encyclopedia: to publish verifiable and not research information.

On the coverage, the study by Halavais and Lackaff (2008) argues that 'Wikipedia's worth lies not only with accuracy, but also in its breadth of subject coverage". They employed two methods to examine the subject coverage of Wikipedia. The first was to compare a sample of Wikipedia's "topical scope and coverage" with a similar sample from Bowker's Books in Print. Generally, they determined that Wikipedia's enormous size means that "even in the least covered areas [. . .] Wikipedia does well". The second aspect of their study compared a topical study of Wikipedia with various scholarly print sources such as Encyclopedia of Linguistics, New Princeton Encyclopedia of Poetry and Poetics, and Encyclopedia of Physics. They determined that Wikipedia's specialized research coverage is more limited than that of these specialized print sources. They explained that by the organic nature of Wikipedia: driven by contributor interest and engagement, some topics develop quickly (popular culture and physical science) whereas others increase more slowly. This surmise is validated by Denning et al. (2005), and Royal and Kapila (2009), who showed that "Some topics are covered more comprehensively than others, and the predictors of these biases include recency, importance, population, and financial wealth", and coherent with the analyses done by Iba et al. (2010); Keegan et al. (2012) (see also the discussion in 4.2).

\subsubsection{Article quality.}

Regarding the evaluation of the articles, one can rely on the internal evaluation proposed by Wikipedia projects (and especially on the Feature Article system), on the criterion used to evaluate these articles. However, Stvilia et al. (2009) showed that the arguments of quality to qualify an article as Feature vary from one language to another (three languages studied, English, Arabic, and Korean). This work was done comparing a subset of FA articles to non-FA articles (or formally FA articles), so it needs to be extended to the whole dataset and to other languages. Hammwöhner, 2007, p. 5, showed that for the English, French and Italian articles, "the differences between

\footnotetext{
31 http://en.Wikipedia.org/wiki/Portal:Contents/Indexes
} 
standard and featured articles are by far greater that those between languages", which suggest different models, each regrouping several language projects, (and may be another field for culture studies approaches). Finally, when external expertise is mobilized to evaluate the quality of Feature Articles, as in Lindsey's work (2010), strong variations appear: on a total of 22 usable responses collected from a variety of discipline, only 12 of 22 were found to pass Wikipedia's own featured article criteria, according to the author.

External criteria, mainly coming from library studies, are based on Katz (2002)'s criteria (e.g., purpose, authority, scope). But Wallace and Van Fleet (2005); Ehmann et al. (2008) concluded that these criteria are difficult to apply to Wikipedia, especially because there is no authorship analysis possible, but also, as pointed by Lewandowski and Spree (2011), "due to the overall scale and the wide range of subject areas, most of the studies focus on specialized fields of knowledge".

Considering this problem, two strategies have been developed to evaluate the quality of Wikipedia, defining a subset of article to be analyzed, either looking at randomly chosen articles, or looking at a sub-project or a topic. In both cases, criteria have to be defined. The most comprehensive attempt to do so may be the ones by Stvilia et al. (2008), and Lewandowski and Spree (2011). The firsts proposed 11 criteria, based on more global analysis of quality in on-line projects (Stvilia et al., 2007), which compared the FA articles to other articles regarding these criteria. The later relied on these criteria, extended them to a list of 13 (see Table 3, page 47), and evaluated the correlation between these criteria and the rank in search engine, with a good correlation but a strong dispersion. As stand by the authors, this does not solve the subjective aspect of the criteria (or the fact their evaluation depends on the evaluator), but the aim is to propose an evaluation grid.

Random analysis. The most famous of this type of evaluation is the one done by Giles (2005), who sent articles from both Wikipedia and Encyclopaedia Britannica to experts and compared their evaluation in terms of errors (factual errors, critical omissions and misleading statements), but also structure and writing, with no considerable difference between the two in terms of errors, even if the Wikipedia articles were perceived as less well written. Also using this random method, Chesney 
Tab. 3: List of applied quality evaluation criteria for an article, from Lewandowski and Spree (2011, table 1, p. 10).

\begin{tabular}{|c|c|}
\hline Labeling/lemmatization & $\begin{array}{l}\text { Obvious/non-ambiguous } \\
\text { Common usage }\end{array}$ \\
\hline Scope Stays focused on the topic (W) & $\begin{array}{l}\text { Stays focused on the topic (W) } \\
\text { No original research (W) }\end{array}$ \\
\hline Comprehensiveness & $\begin{array}{l}\text { Addresses the major aspects of the topic (W) } \\
\text { Understandable as independent text }\end{array}$ \\
\hline Size & $\begin{array}{c}\text { Concise (W) } \\
\text { No longer than } 32 \mathrm{~KB}(\mathrm{~W}) \\
\text { Appropriate to the importance of topic }(\mathrm{W})\end{array}$ \\
\hline Accuracy & $\begin{array}{c}\text { Orthographically and grammatically correct (W) } \\
\text { Consistency (concerning names, quotes, numbers, etc.) (W) }\end{array}$ \\
\hline Recency & $\begin{array}{l}\text { Up to date-ness of cited or recommended resources } \\
\text { Up to date/developments of the last } 3 \text { month are covered }\end{array}$ \\
\hline Clarity and readability & $\begin{array}{c}\text { Concise head lead section (W) } \\
\text { System of hierarchical headings (W) } \\
\text { Informative headlines (W) } \\
\text { Factual } \\
\text { From the specific to the general } \\
\text { Coherent writing }\end{array}$ \\
\hline Writing style & $\begin{array}{c}\text { News style/summary style (W) } \\
\text { Formal, dispassionate, impersonal (W) } \\
\text { Avoiding jargon } \\
\text { Contextualization } \\
\text { Concise } \\
\text { Avoiding ambiguities } \\
\text { Avoiding redundancies } \\
\text { Descriptive, inspiring/interesting } \\
\text { Clear/using examples }\end{array}$ \\
\hline Viewpoint and objectivity & $\begin{array}{c}\text { Neutral } \\
\text { Fair and traceable presentation of controversial views }\end{array}$ \\
\hline Authority & $\begin{array}{c}\text { Verifiable facts }(\mathrm{W}) \\
\text { Reliable sources } \\
\text { Informative academic writing style } \\
\text { Longevity/stability }\end{array}$ \\
\hline Bibliographies & $\begin{array}{c}\text { Uniform way of citation (according to style guide) } \\
\text { Quotations } \\
\text { Further reading } \\
\text { External links }\end{array}$ \\
\hline Access, organization, and accessibility & $\begin{array}{c}\text { Internal links } \\
\text { External links } \\
\text { Table of contents } \\
\end{array}$ \\
\hline Additional material & $\begin{array}{c}\text { Pictures and graphics } \\
\text { Self-explanatory images and graphics } \\
\text { Captions (W) } \\
\text { Copyright statement } \\
\text { Special features } \\
\text { Tabulary overviews }\end{array}$ \\
\hline
\end{tabular}

(Attributes marked with $\mathrm{W}$ are derived from Wikipedia) 
(2006) evaluated that $13 \%$ of the articles used in his study contained mistakes. Results concerning the consistency and comprehensiveness of individual articles have been generally regarded as satisfying (Hammwöhner, 2007).

If Luyt et al. (2008), who proposed a review of the literature on Wikipedia accuracy, concluded that there "is some evidence with regard to formal accuracy (orthography) that Wikipedia is less reliable than comparable works", they joined Fallis (2008, p. 1668) to wonder if the assumption that a high number of orthographic mistakes indicates an equally high number of factual mistakes is valid ${ }^{32}$. However, some work is still needed to automate these syntax error checks, in order to provide better and more global estimation of their number (and also to allow the managers of the project to correct them more efficiently).

Analyses by topic. The analyses by topics are usually micro-analyses and comparisons with established encyclopedias, thus on articles or points where articles exist in both publications. For instance, Bragues (2009) studied seven entries of seven main philosophers and compared them with academic references, evaluating the coverage of these references content by Wikipedia above $50 \%$, and without critical errors.

Regarding history and accuracy, Wikipedia could be ranked, in 2008, between Encarta and American National Biography Online for the USA's history, even if poorly written (Rosenzweig, 2006), which was also the conclusion of Rector (2008), even if a strong set of references to scientific publications is lacking, maybe because these are not freely available (Luyt and Tan, 2010). It seems, however, to remain close to dominant version of the history (what exist in the traditional publications), according to Luyt $(2011)^{33}$. Conclusions are rather the same on the brain and behavioral sciences (Stankus and Spiegel, 2010a, 2010b) where, if Wikipedia relies more strongly on scientific journals in that field, it has less citation that a written-by-experts encyclopedia (Scholarpedia).

\footnotetext{
${ }^{32}$ This is, actually, a main difference with the measures of software quality, such as the number of defects per thousand lines of code (Diaz and Sligo, 1997; Goranson, 1997) or the probability of a fault in a module (Basili, 1992; Basili et al., 1994): in Wikipedia, technical errors (syntax) do not mean, are not the sign of an error in the function, the information delivered).

${ }^{33}$ This is the explanation he gave to the fact that the official version of the history is the only presented for Singapour, when other perspectives are taking into account for Philippine: for the latter, these various points of view are already well existing in the tradition publications.
} 
One area where accuracy is a main concern is medical information, where Wikipedia is today one of the main source (Laurent and Vickers, 2009). A conclusion of its quality (in drug information), by Clauson et al. (2008), is the following: 'Wikipedia has a more narrow scope, is less complete, and has more errors of omission than the comparator database. Wikipedia may be a useful point of engagement for consumers, but is not authoritative and should only be a supplemental source of drug information." More precisely, if looking at the review of the medical literature on Wikipedia Kupferberg and Protus (2011) proposed, it seems that this site does not contain more error than other online Web site, but lacks depth (same result found by Leithner et al. (2010) on the more specific topic of osteosarcoma). However, this does not mean that the information is complete. Lavsa et al. (2011), studying the information available in the English Wikipedia on the 20 most common drugs found that the encyclopedia "does not provide consistently accurate, complete, and referenced medication information", especially on drug interaction, contraindications or dosing and warned against its use by pharmacy students. Devgan et al. (2007) found Wikipedia "accurate though often incomplete medical reference, with a remarkably high level of internal validity" regarding surgical references.

\subsubsection{Conclusion.}

These analyses are not contradictory. First of all, Wikipedia is a project still young and improving: Nielsen (2007) showed an increase over time of the quality of the citations and of the references to scientific journals. Secondly, and coming back to user experience, one has to be careful in comparisons: as pointed out by Fallis (2008), the quality of Wikipedia should not be evaluated in comparison with non accessible encyclopedia, but taking into account the way people use information online (is Wikipedia better than no-Wikipedia). The fact that Wikipedia is less trustworthy than, say Encyclopedia Britannica, seems to be internalized by people (at least faculties), as for the same content, an article branded Wikipedia is view as less accurate that when it is branded Encyclopedia Britannica (Kubiszewski et al., 2011). In addition to this, Wikipedia is quite irreplaceable for accessing information about the fact and figures in entertainment, but also in the scientific actuality. 
It is a project with multi-dimensions, trying to keep memory of breaking news, people, as well as scientific facts and concepts and quite rooted in the actuality. The quality of the articles varies thus also according to external events and is decreasing with the age of the event: Hjørland (2011) showed that the English Wikipedia is the best source when dealing with the research of information on a controversial topic (here breast cancer screening) and, according to Brown's study of political subject (2011), however almost always accurate when the article exists, Wikipedia is better for actual topics than for "older or more obscure subjects". It is also a (one of the?) place(s) where the importance of events is negotiated, leading Pentzold (2009) and Haider and Sundin (2010) to describe Wikipedia as a discursive fabric of collective memory. One of the possible drawbacks of this, as pointed Elvebakk (2008) in his study of articles on philosophers in Wikipedia and two other sources, from the viewpoint of the academic discipline, is the fact that having much more people having an article in Wikipedia, could lead to over-coverage and poor signal on the quality of the persons covered.

In a word, if it is a good point of entry (or at least not worse than another) for specialized knowledge, it should be competed to get accurate information, which was already Clauson et al.'s conclusion for medicine (2008) and Korosec et al.'s for chemical information (2010). This is, actually, exactly what Wikipedia says about itself, as pointed by Murley (2008, p. 596). This what leads Haigh (2011), assessing the quality studying the references founds in Wikipedia's articles to conclude that, regarding the high rate of references of identifiable source, Wikipedia is appropriate for use by nurse students (if they look at the references, which Korosec et al. (2010) showed to be far from obvious). And Devgan et al. (2007) concluded that, given the popularity of the Web site, the medical and surgical professionals should improve the weakest entries (West and Williamson, 2009, propose advices to do, especially when trying to involve students).

\section{Conclusive discussion.}

Most of the analyses we discussed used dump data because they are rather complete on the contributors the most involved, especially on the process part. But, as Preece and Shneiderman (2009) 
claimed, if more studied are still needed to understand the Reader-to-leader process, these analyses may be completed with more qualitative studies and surveys. We found very few works, and this one does not help for that, on the non-text production collaboration, such as the one by Viégas (2007) on the images producers. However, it is worth noting that the results founds on the reasons to participate, the structure of interaction and of governance seem close to the vision administrators have from the inside of the Encyclopedia, (See Mattus, 2009, on the interview of Swedish Wikipedia Administrators).

These results are also coherent with Hess and Ostrom (2006a)'s framework and description of the knowledge commons: if finding the community is easier than other communities of practice (see, for instance, Merriam et al., 2003 on the access to a community of practice of which), there is a period of apprenticeship, to do so, people are nested in small groups, dedicated to topics they were concerned about since the beginning of their participation. Some rules structure this community, but are constantly under discussion and constantly evolving to adapt the project to its environment and its participants.

As announced at the beginning of this article, we did not look at the feedback loop of Hess and Ostrom's model, the impact of Wikipedia on its environment. There are a very actual and active discussions in the librarian and the teaching communities on how integrating the encyclopedia in their professional practices. If we only tangented these debates in this work, especially when looking at Wikipedia quality, we hope that this article may help the discussants to better understand how the project works. The discussion by Konieczny (2009b) of Wikipedia being or not a "social movement" participates to the same questioning about the impact of this collective action on the society, on the way the knowledge is produced and transmitted, but also to a broader discussion of the links between the contribution to online open communities and the involvement of a job (on that respect, see the discussion proposed by Brown Jr. (2008), relying on Himanen (2002), on open-source and Wikipedia participants, where he argued that these hackers are creating new borders between work and leisure).

Finally, being such a successful collective action of creation of a common, Wikipedia has been taken as an emblem of the wisdom of the crowd (Surowiecki, 2004). It is a system, even if an 
imperfect one, which allows more to produce and discuss knowledge, thus, in that sense, empowering more than traditional encyclopedias (Hansen et al., 2009). This does not mean either that everybody has access to the process, as the technological boundaries, but also the organizational ones remain important, a pointed out by Hartelius (2010) and Pfister (2011) as by Perovic (2011). Does that mean, as these two authors debate, that Wikipedia is a thinking machine which overcomes the human fallibility thanks to a technical system, and thus institutes a socio-technical expertise instead of the traditional scientific expertise, and a as argued by Perovic (2011), a world "of contingency without irony, knowledge without self-observation and learning without thinking, a world enshrined by Wikipedia today."? Does this "flawed knowledge communities" (Roberts and Peters, 2011), which is always discussing its perimeter, as Kostakis (2010) showed in his analysis of inclusionists and delationists, or de Laat (2012) on his analysis of the rules regulating new edition, the future deposit of the human knowledge?

In addition to the doubtful argument that a system of production may replace another, comparing Wikipedia with traditional encyclopedias may simply miss the point. As explained by Mattus (2009): it has to be seen as one entry, always evolving to access to knowledge, but which may be combined with others (scientific references, traditional encyclopedias), and used as a tool amongst others, and not, as was the Encyclopédie, the deposit of the human knowledge. What Wikipedia shows is the extension of the knowledge and of the sources of knowledge, since the seventeenth century, and thus the never ending need to educate the users to have a critical, scientific reading of any source of knowledge.

\section{References}

Adler, B. Thomas; Chatterjee, Krishnendu; Alfaro, de Luca; Faella, Marco; Pye, Ian; Raman, Vishwanath (2008a). Assigning trust to wikipedia content. In Proceedings of the 4th International Symposium on Wikis, WikiSym '08, pages 26:1-26:12, New York, NY, USA. ACM.

Adler, B. Thomas; Alfaro, de Luca; Pye, Ian; Raman, Vishwanath (2008b). Measuring author 
contributions to the wikipedia. In Proceedings of the 4 th International Symposium on Wikis, WikiSym '08, pages 15:1-15:10, New York, NY, USA. ACM.

Akrich, Madeleine; Callon, Michel; Latour, Bruno (2006). Sociologie de la traduction : textes fondateurs. Les presses des Mines de Paris, Paris.

Alluvatti, G.M.; Capiluppi, A.; De Ruvo, G.; Molfetta, M. (2011). User generated (web) content: Trash or treasure. In Proceedings of the 12th International Workshop on Principles on Software Evolution, pages 81-90. ACM (2011).

Amichai-Hamburger, Yair; Lamdan, Naama; Madiel, Rinat; Hayat, Tsahi (2008). Personality characteristics of wikipedia members. CyberPsychology \& Behavior, 11(6):679-681.

Anthony, Denise; Smith, Sean W.; Williamson, Timothy (2009). Reputation and reliability in collective goods: The case of the online encyclopedia Wikipedia. Rationality and Society, 21(3): $283-306$.

Antin, Judd (2011). My kind of people? perceptions about wikipedia contributors and their motivations. In Conference on Human Factors in Computing Systems - Proceedings, pages 34113420. ACM (2011).

Antin, Judd; Cheshire, Coye (2010). Readers are not free-riders: Reading as a form of participation on Wikipedia. In Proceedings of the ACM Conference on Computer Supported Cooperative Work, $C S C W$, pages 127-130 (2010).

Antin, Judd; Cheshire, Coye; Nov, Oded (2012). Technology-mediated contributions: Editing behaviors among new wikipedians. In Proceedings of the ACM 2012 conference on Computer Supported Cooperative Work, CSCW'12, pages 373-382, New York, NY, USA. ACM.

Antin, Judd; Yee, R.; Cheshire, Coye; Nov, Oded (2011). Gender differences in Wikipedia editing. In WikiSym 2011 Conference Proceedings - 7th Annual International Symposium on Wikis and Open Collaboration, pages 11-14. ACM (2011). 
Arafat, O.; Riehle, Dirk (2009). The commit size distribution of open source software. In 42nd Hawaii International Conference on System Sciences (HICSS), pages 1 - 8, Waikoloa, Hawaii, USA. IEEE. URL: http://flosshub.org/sites/flosshub.org/files/07-07-07.pdf.

Arazy, O.; Nov, O. (2010). Determinants of Wikipedia quality: The roles of global and local contribution inequality. In Proceedings of the ACM Conference on Computer Supported Cooperative Work, CSCW, pages 233-236 (2010).

Arazy, O.; Nov, O.; Patterson, R.; Yeo, L. (2011). Information quality in Wikipedia: The effects of group composition and task conflict. Journal of Management Information Systems, 27(4):71-98.

Ashton, D. (2011). Awarding the self in wikipedia: Identity work and the disclosure of knowledge. First Monday, 16(1). URL: http://firstmonday.org/htbin/cgiwrap/bin/ojs/index.php/ $\mathrm{fm} / \mathrm{article/view/3156/2747.}$

Auray, N.; Hurault-Plantet, M.; Poudat, C.; Jacquemin, B. (2009). La négociation des points de vue, une cartographie sociale des confits et des querelles dans le wikipédia francophone. Reseaux, $154(2): 15-50$.

Barabási, A. L.; Albert, R. (1999). Emergence of scaling in random networks. Science, (286(5439)): $509-512$.

Barcellini, Flore; Détienne, Françoise; Burkhardt, Jean-Marie (2008). User and developer mediation in an open source software community: Boundary spanning through cross participation in online discussions. International Journal of Human-Computer Studies, 66:558-570.

Basili, Victor R. (1992). Software modeling and measurement: the Goal/Question/Metric paradigm. Technical report, Techreport UMIACS TR-92-96, University of Maryland at College Park, College Park, MD, USA.

Basili, V. R.; Caldiera, G.; Rombach, H. D. (1994). Goal question metric paradigm, In Marciniak, J. J., editor, Encyclopedia of Software Engineering, Vol. 1, pages 528-532. John Wiley, New York. 
Baytiyeh, H.; Pfaffman, J. (2010). Volunteers in wikipedia: Why the community matters. Educational Technology and Society, 13(2):128-140.

Becker, H. S. (1960). Notes on the concept of commitment. American Journal of Sociology, 66(1): $32-40$.

Becker, H. S. (1963). Outsiders. Studies in the Sociology of Deviance. Free Press.

Benker, Yochai; Nissenbaum, Helen (2006). Commons-based peer production and virtue. The Journal of Political Philosophy, 14(4):394-419.

Besten, Matthijs Den; Dalle, Jean-Michel (2008). Keep it simple: A companion for simple wikipedia? Industry \& Innovation, 15(2):169-178.

Billings, M.; Watts, L. A. (2010). Understanding dispute resolution online: Using text to reflect personal and substantive issues in conflict. In Conference on Human Factors in Computing Systems - Proceedings, volume 3, pages 1447-1456 (2010).

Black, Laura W.; Welser, Howard T.; Cosley, Dan; DeGroot, Jocelyn M. (2011). Self-governance through group discussion in wikipedia measuring deliberation in online group. Small Group Research, 42(5):595-634.

Blumenstock, J. E. (2008). Size matters: Word count as a measure of quality on wikipedia. In Proceeding of the 17th International Conference on World Wide Web 2008, WWW'08, pages 1095-1096 (2008).

Bragues, George (2009). Wiki-philosophizing in a marketplace of ideas: evaluating wikipedia's entries on seven great minds. MediaTropes eJournal, 2(1):117-158.

Brandes, Ulrik; Lerner, Jürgen (2008). Visual analysis of controversy in user-generated encyclopedias. Information Visualization, 7:34-48.

Brändle, Andreas (2005). Too many cooks don't spoil the broth. In Proceedings of Wikimania 2005 - The First International Wikimedia Conference, Frankfurt, Germany. 
Brown, Adam R. (2011). Wikipedia as a data source for political scientists: Accuracy and completeness of coverage. Political Science \& 8 Politics, 44(02):339-343.

Brown Jr., James (2008). From friday to sunday: The hacker ethic and shifting notions of labour, leisure and intellectual property. Leisure Studies, 27(4):395-409.

Bryant, Susan L.; Forte, A.; Bruckman, A. (2005). Becoming wikipedian: Transformation of participation in a collaborative online encyclopedia. In proceedings of the 2005 international ACM SIGGROUP conference on Supporting group work, New York, NY, USA. ACM.

Buriol, Luciana; Castillo, Carlos; Donato, Debora; Leonardi, Stefano; Millozzi, Stefano (2006). Temporal Evolution of the Wikigraph. In Proceedings of Web Intelligence, pages 45-51, Hong Kong. IEEE CS Press. URL: http://www.chato.cl/papers/buriol_2006_temporal_ analysis_wikigraph.pdf.

Burke, M.; Kraut, Robert (2008). Taking up the mop: Identifying future wikipedia administrators. In Conference on Human Factors in Computing Systems - Proceedings, pages 3441-3446 (2008).

Burt, R. S. (2009). Neighbor Networks: Competitive Advantage Local and Personal. Oxford University Press.

Butler, Brian; Joyce, Elisabeth; Pike, Jacqueline (2008). Don’t look now, but we've created a bureaucracy: The nature and roles of policies and rules in Wikipedia. In Proceeding of the twenty-sixth annual SIGCHI conference on Human factors in computing systems, CHI '08, pages 1101-1110, New York, NY, USA. ACM.

Buzzi, M. C.; Buzzi, M.; Leporini, B.; Senette, C. (2008). Making wikipedia editing easier for the blind. In ACM International Conference Proceeding Series, volume 358, pages 423-426 (2008). Cited By (since 1996): 1.

Cabunducan, G.; Castillo, R.; Lee, J.B. (2011). Voting behavior analysis in the election of Wikipedia admins. In Proceedings - 2011 International Conference on Advances in Social Networks Analysis and Mining, pages 545-547. IEEE (2011). 
Callahan, Ewa S.; Herring, Susan C. (2011). Cultural bias in wikipedia content on famous persons. Journal of the American Society for Information Science and Technology, 62(10):1899-1915.

Callis, Kristine L.; Christ, Lindsey R.; Resasco, Julian; Armitage, David W.; Ash, Jeremy D.; Caughlin, Timothy T.; Clemmensen, Sharon F.; Copeland, Stella M.; Fullman, Timothy J.; Lynch, Ryan L.; Olson, Charley; Pruner, Raya A.; Vieira-Neto, Ernane H.M.; West-Singh, Raneve; Bruna, Emilio M. (2009). Improving wikipedia: educational opportunity and professional responsibility. Trends in Ecology $\mathscr{G}$ Evolution, 24(4):177 - 179.

Callon, Michel; Law, John; Rip, Arie (1986). Mapping the Dynamics of Science and Technology. MacMillan.

Capocci, A.; Servedio, V. D. P.; Colaiori, F.; Buriol, L. S.; Donato, D.; Leonardi, S.; Caldarelli, G. (2006). Preferential attachment in the growth of social networks: The internet encyclopedia wikipedia. Phys. Rev. E, 74:036116.

Cardon, Dominique (2012). Discipline but not punish. The governance of Wikipedia. In MassitFolléat, Françoise; Méadel, Cécile; Monnoyer-Smith, Laurence, editors, Normative Experience in Internet Politics. Presses des Mines, Paris.

Cardon, Dominique; Levrel, Julien (2009). La vigilance participative. une interprétation de la gouvernance de wikipédia. Réseaux, 2(154):9-12.

Carillo, Kevin; Okoli, Chitu (2011). Generating quality open content: A functional group perspective based on the time, interaction, and performance theory. Information $\&$ Management, 48(6): $208-219$.

Chen, Jilin; Ren, Yuqing; Riedl, John (2010). The effects of diversity on group productivity and member withdrawal in online volunteer groups. In Conference on Human Factors in Computing Systems - Proceedings, volume 2, pages 821-830 (2010).

Chesney, Thomas (2006). An empirical examination of wikipedia's credibility. First Monday, 
11(11). URL: http://www .firstmonday .org/htbin/cgiwrap/bin/ojs/index.php/fm/issue/ view/205.

Cho, H.; Chen, M.; Chung, S. (2010). Testing an integrative theoretical model of knowledge-sharing behavior in the context of wikipedia. Journal of the American Society for Information Science and Technology, 61(6):1198-1212.

Choi, B.; Alexander, K.; Kraut, R. E.; Levine, J. M. (2010). Socialization tactics in Wikipedia and their effects. In Proceedings of the ACM Conference on Computer Supported Cooperative Work, $C S C W$, pages $107-116(2010)$.

Ciffolilli, A. (2003). Phantom authority, selfselective recruitment and retention of members in virtual communities: The case of wikipedia. First Monday, 8(12). URL: http://firstmonday . org/htbin/cgiwrap/bin/ojs/index.php/fm/article/view/1108/1028.

Clauson, K. A.; Polen, H. H.; Kamel Boulos, M. N.; Dzenowagis, J. H. (2008). Scope, completeness, and accuracy of drug information in wikipedia. Annals of Pharmacotherapy, 42(12):1814-1821.

Collier, Benjamin; Bear, Julia (2012). Conflict, criticism, or confidence: An empirical examination of the gender gap in Wikipedia contributions. In Proceedings of the ACM 2012 conference on Computer Supported Cooperative Work, CSCW '12, pages 383-392, New York, NY, USA. ACM.

Cross, Tom (2006). Puppy smoothies: Improving the reliability of open, collaborative wikis. First Monday, 11(9). URL: http://frodo.lib.uic.edu/ojsjournals/index.php/fm/article/ view/1400.

Crowston, Kevin; Heckman, Robert; Misiolek, Nora (2010). Leadership in self-managing virtual teams. Syracuse University School of Information Studies working paper.

Crowston, Kevin; Howison, James; Annabi, Hala (2006). Success in free and open source software development: Theory and measures. Software Process Improvement and Practice, 11:123-148.

Crowston, Kevin; Jullien, Nicolas; Ortega, Felipe (2013). Is wikipedia inefficient? modelling effort 
and participation in wikipedia. In Forty-sixth Hawai'i International Conference on System Sciences (HICSS-46). IEEE Computer society (2013). URL: http://ssrn. com/abstract=1960696.

Dalip, D. H.; Gonçalves, M. A.; Cristo, M.; Calado, P. (2009). Automatic quality assessment of content created collaboratively by web communities: A case study of wikipedia. In Proceedings of the ACM/IEEE Joint Conference on Digital Libraries, pages 295-304 (2009).

Davis, F. D. (1989). Perceived usefulness, perceived ease of use, and user acceptance of information technology. MIS Quarterly, 13(3):319-340.

Davis, James H.; Schoorman, F. David; Donaldson, Lex (1997). Toward a stewardship theory of management. The Academy of Management Review, 22(1):20-47.

Laat, de Paul (2012). Coercion or empowerment? moderation of content in wikipedia as 'essentially contested' bureaucratic rules. Ethics and Information Technology, pages 1-13.

Laat, de Paul B. (2010). How can contributors to open-source communities be trusted? on the assumption, inference, and substitution of trust. Ethics and Inf. Technol., 12:327-341.

Dede, Chris (2008). A seismic shift in epistemology. EDUCAUSE Review, 43:8081. URL: http://www . educause .edu/EDUCAUSE+Review/EDUCAUSEReviewMagazineVolume43/ ASeismicShiftinEpistemology/162892.

Dejean, Sylvain; Jullien, Nicolas (2012). Enrolled since the beginning. an assessement of the wikipedia contributors' behavior regarding their first contribution. Marsouin working paper (2012). URL: http://papers.ssrn.com/sol3/papers.cfm?abstract_id=1980806.

DeLone, W. H.; McLean, Ephraim R. (1992). Information systems success: The quest for the dependent variable. Information Systems Research, 3(1):60-95.

DeLone, W. H.; McLean, Ephraim R. (2002). Information systems success revisited. In Proceedings of the 35th Hawaii International Conference on System Sciences, Waikola, Hawaii. HICSS-35. URL: http://csd12. computed.org/comp/proceedings/hicss/2002/1435/08/14350238.pdf. 
DeLone, W. H.; McLean, Ephraim R. (2003). The delone and mclean model of information systems success: a ten-year update. Journal of Management Information Systems, 19(4):9-30.

Den Besten, M.; Gaio, L.; Rossi, A.; Dalle, J. . (2010). Using metadata signals to support stigmergy. In Proceedings - 2010 4th IEEE International Conference on Self-Adaptive and Self-Organizing Systems Workshop, SASOW 2010, pages 131-135 (2010).

Denning, Peter; Horning, Jim; Parnas, David; Weinstein, Lauren (2005). Wikipedia risks. Commun. ACM, 48:152-152.

Devereaux, Zachary; Niederer, Sabine; Nijhof, Bram; Rogers, Richard; Touwslager, Auke (2008). Networked content. Technical report. URL: http://wiki.digitalmethods.net/Dmi/ NetworkedContent.

Devgan, L.; Powe, N.; Blakey, B.; Makary, M. (2007). Wiki-surgery? internal validity of wikipedia as a medical and surgical reference. Journal of the American College of Surgeons, 205(3):S76-S77.

Diaz, Michael; Sligo, Joseph (1997). How software process improvement helped motorola. IEEE Softw., 14:75-81.

Dieste, O.; Padua, A.G. (2007). Developing search strategies for detecting relevant experiments for systematic reviews. pages 215-224. Juristo et al. (2007) (2007).

Dooley, P. L. (2010). Wikipedia and the two-faced professoriate. In Proceedings of WikiSym 2010 - The 6th International Symposium on Wikis and Open Collaboration. ACM (2010).

Douglas, M. (1970). Barrie \& Rockliff, London.

Douglas, M. (1978). Royal Anthropological Institute, London.

Doyle, B. (2008). Wikiful thinking. EContent, 31(1):37.

Druck, Gregory; Miklau, Gerome; McCallum, Andrew (2008). Learning to Predict the Quality of Contributions to Wikipedia. In WikiAI'08: Proceedings of the Workshop on Wikipedia and Artificial Intelligence: An Evolving Synergy, pages 7-12. AAAI Press (2008). 
Ehmann, Katherine; Large, Andrew; Beheshti, Jamshid (2008). Collaboration in context: Comparing article evolution among subject disciplines in wikipedia. First Monday, 13(10). URL: http: //firstmonday.org/htbin/cgiwrap/bin/ojs/index.php/fm/article/view/2217/2034.

Eijkman, Henk (2008). Web 2.0 as a non-foundational network-centric learning space. Campus-Wide Information Systems, 25(2):93 - 104.

Elvebakk, Beate (2008). Philosophy democratized? First Monday, 13(2). URL: http:// firstmonday .org/htbin/cgiwrap/bin/ojs/index.php/fm/article/view/2365/2182.

Fallis, Don (2008). Toward an epistemology of wikipedia. Journal of the American Society for Information Science and Technology, 59(10):1662-1674.

Fang, Yulin; Neufeld, Derrick (2009). Understanding Sustained Participation in Open Source Software Projects. Journal on Management Information Systems, 25(4):9-50.

Feller, J.; Fitzgerald, R.; Hissam, S.; Lakhani, R. K., editors (2005). Perspectives on free and open source software. MIT Press, New York.

Ferriter, Meghan M. (2009). "Arguably the Greatest": Sport Fans and Communities at Work on Wikipedia. Sociology of Sport Journal, 26(1):127-154.

Fiedler, Tom (2008). The web's pathway to accuracy. Nieman Reports, 62.

Flanagin, A. J.; Metzger, M. J. (2011). From encyclopædia britannica to wikipedia: Generational differences in the perceived credibility of online encyclopedia information. Information Communication and Society, 14(3):355-374.

Fong, Peter Kin-Fong; Biuk-Aghai, Robert P. (2010). What did they do? deriving high-level edit histories in wikis. In Proceedings of the 6th International Symposium on Wikis and Open Collaboration, WikiSym '10, pages 2:1-2:10, New York, NY, USA. ACM.

Forte, A.; Bruckman, A. (2005). Why do people write for Wikipedia? Incentives to contribute to open-content publishing. working paper. 
Forte, Andrea; Kittur, Niki; Larco, Vanessa; Zhu, Haiyi; Bruckman, Amy; Kraut, Robert E. (2012). Coordination and beyond: social functions of groups in open content production. In Proceedings of the ACM 2012 conference on Computer Supported Cooperative Work, CSCW '12, pages 417426, New York, NY, USA. ACM.

Forte, Andrea; Larco, Vanesa; Bruckman, Amy (2009). Decentralization in wikipedia governance. Journal of Management Information Systems, 26(1):49-72.

Francke, H.; Sundin, O. (2010). An inside view: Credibility in wikipedia from the perspective of editors. Information Research, 15(3). URL: http://InformationR.net/ir/15-3/colis7/ colis702.html.

Franco, V.; Piirto, H.-Y., R.and Hu; Lewenstein, B.V.; Underwood, R.; Vidal, N.K. (1995). Anatomy of a flame: conflict and community building on the internet. Technology and Society Magazine, IEEE, 14(2):12 - 21.

Fréard, Dominique; Denis, Alexandre; Détienne, Françoise; Baker, Michael; Quignard, Matthieu; Barcellini, Flore (2010). The role of argumentation in online epistemic communities: the anatomy of a conflict in wikipedia. In Proceedings of the 28th Annual European Conference on Cognitive Ergonomics, ECCE '10, pages 91-98, New York, NY, USA. ACM.

Gastil, J.; Black, L. (2008). Public deliberation as the organizing principle of political communication research. Journal of Public Deliberation, 4. URL: http://services.bepress.com/jpd/ vol4/iss1/art3.

Geeb, F. (1998). Semantische und enzyklopädische Informationen in Fachwörterbüchern: Eine Untersuchung zu fachinformativen Informationstypen mit besonderer BerÃEcksichtigung wortgebundener Darstellungsformen. Århus: Wirtschaftsuniversität.

Geiger, R.Stuart (2011). The Lives of Bots, In (Lovink and Tkacz, 2011), , editor, Critical Point of View: A Wikipedia Reader. 
Geiger, R. Stuart; Ford, H. (2011). Participation in wikipedia's article deletion processes. In WikiSym 2011 Conference Proceedings - 7th Annual International Symposium on Wikis and Open Collaboration, pages 201-202 (2011).

Geiger, R. Stuart; Ribes, David (2010). The work of sustaining order in wikipedia: The banning of a vandal. In Proceedings of CSCW 2010, February 6-10, Savannah, Georgia, USA. ACM.

Gibb, Jack R. (1961). Defensive Communication. Journal of Communication, 11(3):141-148.

Giles, Jim (2005). Internet encyclopaedias go head to head. Nature, 438:900-901.

Gleave, Eric; Welser, Howard T.; Lento, Thomas M.; Smith, Marc A. (2009). A conceptual and operational definition of 'social role' in online community. Hawaii. 42nd Hawaii International Conference on System Sciences, IEEE.

Glott, Ruediger; Schmidt, Philipp; Ghosh, Rishab (2010a). Analysis of wikipedia survey data. topic: Quality of wikipedia content. Technical report, UNU-MERIT. URL: http://www . wikipediasurvey.org/docs/Wikipedia_Overview_15March2010-FINAL.pdf.

Glott, Ruediger; Schmidt, Philipp; Ghosh, Rishab (2010b). Wikipedia survey - overview of results. Technical report, UNU-MERIT. URL: http://www.wikipediasurvey.org/docs/Wikipedia_ Overview_15March2010-FINAL.pdf.

Goldspink, Chris; Edmonds, Bruce; Gilbert, Nigel (2010). Normative behaviour in wikipedia. Information Communication and Society, 13(5):652-673.

Gómez, Vicenç; Kappen, Hilbert J.; Kaltenbrunner, Andreas (2011). Modeling the structure and evolution of discussion cascades. In Proceedings of the 22nd ACM conference on Hypertext and hypermedia, HT '11, pages 181-190, New York, NY, USA. ACM.

Goranson, H. T. (1997). Design for Agility Using Process Complexity Measures. Agility $\& 3$ Global Competition, 1(3):1-9. 
Gorgeon, A.; Swanson, E. B. (2009). Organizing the vision for web 2.0: A study of the evolution of the concept in Wikipedia. In Proceedings of the 5th International Symposium on Wikis and Open Collaboration, WiKiSym 2009 (2009).

Gorman, G.E. (2007). A tale of information ethics and encyclopaedias; or, is itwikipedia/it just another internet scam? Online Information Review, 31(3):273-276. URL: http://www . ingentaconnect.com/content/mcb/264/2007/00000031/00000003/art00001.

Granovetter, M. (1985). Economic action and social structure: The problem of embeddedness. American Journal of Sociology, 91:481-510.

Grant, R.M. (1996). Toward a knowledge-based theory of the firm. Strategic Management Journal, 17(Winter):109-122.

Hackman, J. R. (1987). The design of work teams, In Lorsch, J. W., editor, Handbook of Organizational Behavior, pages 315-342. Prentice Hall, Englewood Cliffs, NJ.

Haider, Jutta; Sundin, Olof (2010). Beyond the legacy of the enlightenment? online encyclopaedias as digital heterotopias. First Monday, 15(1). URL: http://firstmonday.org/htbin/cgiwrap/ bin/ojs/index.php/fm/article/viewArticle/2744/242.

Haigh, Carol A. (2011). Wikipedia as an evidence source for nursing and healthcare students. Nurse Education Today, 31(2):135 - 139.

Halatchliyski, I.; Moskaliuk, J.; Kimmerle, J.; Cress, U. (2010). Who integrates the networks of knowledge in wikipedia? In Proceedings of WikiSym 2010 - The 6th International Symposium on Wikis and Open Collaboration (2010).

Halavais, Alex (2004). The isuzu experiment. URL: http://alex.halavais.net/index.php?p= 794, blog entry at A Thaumaturgical Compendium, accessed March, 162012.

Halavais, Alexander; Lackaff, Derek (2008). An analysis of topical coverage of wikipedia. Journal of Computer-Mediated Communication, 13(2):429-440. 
Halfaker, A.; Kittur, A.; Kraut, R.; Riedl, J. (2009). A jury of your peers: Quality, experience and ownership in wikipedia. In Proceedings of the 5th International Symposium on Wikis and Open Collaboration, WiKiSym 2009 (2009).

Halfaker, Aaron; Kittur, Aniket; Riedl, John (2011). Don't bite the newbies: How reverts affect the quantity and quality of wikipedia work. In Proceedings of the 7th International Symposium on Wikis and Open Collaboration, WikiSym '11, New York, NY, USA. ACM.

Hammwöhner, Rainer (2007). Interlingual aspects of wikipedia's quality. In Proceedings of the 12th International Conference on Information Quality, MIT, Cambridge, MA, USA, November 9-11, 2007, pages 477-488. MIT (2007).

Hansen, Sean; Berente, Nicholas; Lyytinen, Kalle (2009). Wikipedia, critical social theory, and the possibility of rational discourse. Information Society, 25(1):38-59.

Hara, Noriko; Shachaf, Pnina; Hew, Khe Foon (2010). Cross-cultural analysis of the Wikipedia community. Journal of the American Society of Information Science and Technology, 61(10): $2097-2108$.

Hardy, Darren; Frew, James; Goodchild, Michael F. (2012). Volunteered geographic information production as a spatial process. International Journal of Geographical Information Science, forth.

Harrer, A.; Moskaliuk, J.; Kimmerle, J.; Cress, U. (2008). Visualizing wiki-supported knowledge building: Co-evolution of individual and collective knowledge. In WikiSym 2008 - The 4th International Symposium on Wikis, Proceedings (2008).

Hartelius, E. J. (2010). Wikipedia and the emergence of dialogic expertise. Southern Communication Journal, $75(5): 505-526$.

Hasan, H.; Pfaff, C. (2006a). Emergent conversational technologies that are democratising information systems in organisations: the case of the corporate wiki. In Faculty of commerce papers. University of Wollongong (2006a). 
Hasan, H.; Pfaff, C. (2006b). The wiki: A tool to support the activities of the knowledge worker. In Proceedings of Transformational Tools for the 21st Century, pages 38-48, Queensland, Australie. TT211C2006.

Hasan, H.; Pfaff, C. (2006c). The wiki: an environment to revolutionise employees' interaction with corporate knowledge. In Proceedings of the Australasian Computer-Human Interaction Conference, Sydney. OZCHI 2006.

Hecht, B; Gergle, D. (2010a). The Tower of Babel meets Web 2.0: user-generated content and its applications in a multilingual context. In Proceedings of conference on human factors in computing systems (CHI 2010), New York. ACM.

Hecht, Brent J.; Gergle, Darren (2010b). On the "localness" of user-generated content. In Proceedings of the 2010 ACM conference on Computer supported cooperative work, CSCW '10, pages 229-232, New York, NY, USA. ACM.

Hernandez, Morela (2012). Toward an Understanding of the Psychology of Stewardship. The Academy of Management Review (AMR), 37(2):172-193.

Hess, Charlotte; Ostrom, Elinor (2006a). A Framework for Analyzing the Knowledge Commons. In (Hess and Ostrom, 2006c), , editor, Understanding Knowledge as a Commons. From Theory to Practice, pages 41-81.

Hess, Charlotte; Ostrom, Elinor (2006b). Introduction: An Overview of the Knowledge Commons. In (Hess and Ostrom, 2006c), , editor, Understanding Knowledge as a Commons. From Theory to Practice, pages 3-26.

Hess, Charlotte; Ostrom, Elinor, editors (2006c). Understanding Knowledge as a Commons. From Theory to Practice. MIT Press.

Himanen, Pekka (2002). The Hacker Ethic and the Spirit of the Information Age. Random House.

Hinds, Pamela J.; Bailey, Diane E. (2003). Out of sight, out of sync: Understanding conflict in distributed teams. Organization Science, 14:615-632. 
Hinds, Pamela J.; Mortensen, Marc (2005). Understanding conflict in geographically distributed teams: The moderating effects of shared identity, shared context, and spontaneous communication. Organization Science, 16:290-307.

Hjørland, Birger (2011). Evaluation of an information source illustrated by a case study: Effect of screening for breast cancer. Journal of the American Society for Information Science and Technology, 62(10):1892-1898.

Ho, SC; Ting, PH; Bau, DY; Wei, CC (2011). Knowledge-sharing intention in a virtual community: A study of participants in the chinese wikipedia. Cyberpsychology Behavior and social networking, $14(9): 541-545$.

Hofmann, Philipp; Riehle, Dirk (2009). Estimating Commit Sizes Efficiently. In Open Source Ecosystems: Diverse Communities Interacting (IFIP 2.13), volume 299/2009 of IFIP Advances in Information and Communication Technology, pages 105 - 115. Springer, Springer (2009). URL: http: //flosshub.org/sites/flosshub.org/files/EstimatingCommitSizesEffciently.pdf.

Hofstede, G. (1991). Cultures and organizations: Software of the mind. McGraw-Hill, London.

Hofstede, G.; McCrae, R. (2004). Personality and culture revisited: Linking traits and dimensions of culture. Cross-Cultural Research, 38(1):52-88.

Hu, M.; Lim, E.-P.; Sun, A.; Lauw, H. W.; Vuong, B. (2007). Measuring article quality in wikipedia: Models and evaluation. In International Conference on Information and Knowledge Management, Proceedings, pages 243-252 (2007).

Hutchins, E. (1996). Cognition in the Wikd. The MIT Press.

Huvila, Isto (2010). Where does the information come from? information source use patterns in wikipedia. Information Research, 15(3). URL: http://InformationR.net/ir/15-3/paper433. html.

Iba, Takashi; Nemoto, Keiichi; Peters, Bernd; Gloor, Peter A. (2010). Analyzing the creative editing 
behavior of wikipedia editors through dynamic social network analysis. In Procedia - Social and Behavioral Sciences, volume 2, pages 6441-6456 (2010).

Jahnke, Isa (2010). Dynamics of social roles in a knowledge management community. Computers in Human Behavior, 26(4):533-546.

Javanmardi, S.; Ganjisaffar, Y.; Lopes, C.; Baldi, P. (2009). User contribution and trust in Wikipedia. In 5th International Conference on Collaborative Computing: Networking, Applications and Worksharing (2009).

Jones, John (2008). Patterns of revision in online writing: A study of wikipedia's featured articles. Written Communication, 25:262-289.

Joyce, Elisabeth; Butler, Brian; Pike, Jacqueline (2011). Handling flammable materials: Wikipedia biographies of living persons as contentious objects. In Proceedings of the 2011 iConference, iConference '11, pages 25-32, New York, NY, USA. ACM.

Jullien, Nicolas; Roudaut, Karine; le Squin, Sandrine (2011). L'engagement dans des collectifs de production de connaissance en ligne. Le cas GeoRezo. Revue française de socio-économie, 8(2): $59-83$.

Juristo, N.; Seaman, C.B.; Vegas, S., editors (2007). First international symposium on empirical software engineering and measurement (ESEM' 2007). IEEE Computer Society, Madrid, Spain.

Kamata, M.; Kato, D.; Kunieda, K.; Yamada, K. (2010). Web community contributor's motivation: Japanese wikipedia case study. In Proc. of the IADIS Int. Conf. Collaborative Technologies 2010, Proc. of the IADIS Int. Conf. Web Based Communities 2010, Part of the MCCSIS 2010, pages 29-33 (2010).

Katz, William A. (2002). Introduction to reference work, vol. 1: Basic Information Services. McGraw-Hill, Boston, MA, 8th edition.

Keegan, B.; Gergle, D. (2010). Egalitarians at the gate: One-sided gatekeeping practices in social 
media. In Proceedings of the ACM Conference on Computer Supported Cooperative Work, CSCW, pages 131-134 (2010).

Keegan, Brian; Gergle, Darren; Contractor, Noshir (2012). Do editors or articles drive collaboration?: multilevel statistical network analysis of wikipedia coauthorship. In Proceedings of the ACM 2012 conference on Computer Supported Cooperative Work, CSCW '12, pages 427-436, New York, NY, USA. ACM.

Kittur, A.; Chi, E. H.; Pendleton, B. A.; Suh, B.; Mytkowicz, T. (2007a). Power of the few vs. wisdom of the crowd: Wikipedia and the rise of the bourgeoisie. In CHI 2007, San Jose, CA, USA.

Kittur, Aniket; Kraut, Robert E. (2008). Harnessing the wisdom of crowds in wikipedia: quality through coordination. In Proceedings of the 2008 ACM conference on Computer supported cooperative work, CSCW '08, pages 37-46, New York, NY, USA. ACM.

Kittur, A.; Pendleton, B.; Kraut, R. E. (2009). Herding the cats: The influence of groups in coordinating peer production. In Proceedings of the 5th International Symposium on Wikis and Open Collaboration, WiKiSym 2009 (2009).

Kittur, A.; Suh, B.; Pendleton, B.; Chi, E. H. (2007b). He says, she says: Conflict and coordination in wikipedia. In $\mathrm{CHI} 2007$, San Jose, CA, USA.

Konieczny, Piotr (2009a). Governance, organization, and democracy on the Internet: The iron law and the evolution of Wikipedia. Sociological Forum, 24(1):162-192.

Konieczny, Piotr (2009b). Wikipedia: community or social movement? Interface, 1(2):212-232.

Konieczny, P. (2010). Adhocratic governance in the internet age: A case of wikipedia. Journal of Information Technology and Politics, 7(4):263-283.

Korfiatis, N. T.; Poulos, M.; Bokos, G. (2006). Evaluating authoritative sources using social networks: An insight from Wikipedia. Online Information Review, 30(3):252-262. 
Korosec, L.; Limacher, P. A.; Lüthi, H. P.; Brändle, M. P. (2010). Chemical information media in the chemistry lecture hall: A comparative assessment of two online encyclopedias. Chimia, 64 (5):309-314.

Kostakis, Vasilis (2010). Identifying and understanding the problems of wikipedia's peer governance: The case of inclusionists versus deletionists. First Monday, 15(3). URL: http://firstmonday . org/htbin/cgiwrap/bin/ojs/index.php/fm/article/view/2613/2479.

Kriplean, T.; Beschastnikh, I.; McDonald, D. W.; Golder, S. A. (2007). Community, consensus, coercion, control: $\mathrm{Cs}^{*} \mathrm{w}$ or how policy mediates mass participation. In GROUP'07 - Proceedings of the 2007 International ACM Conference on Supporting Group Work, pages 167-176 (2007).

Kubiszewski, Ida; Noordewier, Thomas; Costanza, Robert (2011). Perceived credibility of internet encyclopedias. Computers \& Education, 56(3):659-667.

Kupferberg, Natalie; Protus, Bridget McCrate (2011). Accuracy and completeness of drug information in wikipedia: an assessment. Medical Library Association, 99(4):310-313.

Lakhani, Karim; Wolf, R. (2005). Why Hackers Do What They Do: Understanding Motivation and Effort in Free/Open Source Software Projects, in Feller et al. (2005) edition, pages 3-22.

Lam, S. K.; Karim, J.; Riedl, J. (2010). The effects of group composition on decision quality in a social production community. In Proceedings of the 16th ACM International Conference on Supporting Group Work, GROUP'10, pages 55-64 (2010).

Lam, Shyong K.; Riedl, John (2011). The past, present, and future of wikipedia. Computer, 44(3): $87-90$.

Lam, Shyong K.; Uduwage, Anuradha; Dong, Zhenhua; Sen, Shilad; Musicant, David R.; Terveen, Loren; Riedl, John (2011). WP:Clubhouse? An Exploration of Wikipedia's Gender Imbalance. In Proceedings of the 7th International Symposium on Wikis and Open Collaboration, WikiSym '11, New York, NY, USA. ACM. 
Laniado, David; Tasso, Riccardo (2011). Co-authorship 2.0: Patterns of collaboration in Wikipedia. In Proceedings of the 22nd ACM conference on Hypertext and hypermedia, HT '11, pages 201-210, New York, NY, USA. ACM.

Latour, Bruno (2005). Reassembling the Social: An Introduction to Actor-Network-Theory. Oxford University Press, New York, NY.

Laurent, M. R.; Vickers, T. J. (2009). Seeking health information online: Does wikipedia matter? Journal of the American Medical Informatics Association, 16(4):471-479.

Lave, J.; Wenger, Etienne (1991). Situated learning: legitimate peripheral participation. Cambridge University Press, New York.

Lavsa, S. M.; Corman, S. L.; Culley, C. M.; Pummer, T. L. (2011). Reliability of wikipedia as a medication information source for pharmacy students. Currents in Pharmacy Teaching and Learning, 3(2):154-158.

Lee, Sang-Yong Tom; Kim, Hee-Woong; Gupta, Sumeet (2009). Measuring open source software success. Omega, $37(2): 426-438$.

Leithner, A.; Maurer-Ertl, W.; Glehr, M.; Friesenbichler, J.; Leithner, K.; Windhager, R. (2010). Wikipedia and osteosarcoma: A trustworthy patients' information? Journal of the American Medical Informatics Association, 17(4):373-374.

Leskovec, Jure; Huttenlocher, Daniel; Kleinberg, Jon (2010a). Governance in Social Media: A Case Study of the Wikipedia Promotion Process. In Proceedings of the International AAAI Conference on Weblogs and Social Media (2010a).

Leskovec, Jure; Huttenlocher, Daniel; Kleinberg, Jon (2010b). Signed networks in social media. In Proceedings of the 28th international conference on Human factors in computing systems, CHI '10, pages 1361-1370, New York, NY, USA. ACM. ISBN 978-1-60558-929-9.

Letessier, Ivan (2007). Cette fois, le quid est cuit. Capital.fr. URL: http://www.capital.fr/ enquetes/derapages/cette-fois-le-quid-est-cuit-390762. 
Lewandowski, Dirk; Spree, Ulrike (2011). Ranking of Wikipedia articles in search engines revisited: Fair ranking for reasonable quality? Journal of the American Society for Information Science and Technology, 62(1):117-132.

Liang, C.; Chen, C.; Hsu, Y. (2008). The participation motivation and work styles of the administrators for chinese wikipedia. Journal of Educational Media and Library Science, 46(1): $81-110$.

Chen, liang Hsin (2010). The perspectives of higher education faculty on wikipedia. The Electronic Library, 28(3):361-373.

Liao, Han-Teng (2009). Conflict and consensus in the chinese version of wikipedia. IEEE Technology and Society Magazine, 28.

Lieberman, M.D.; Lin, J. (2009). You are where you edit: Locating Wikipedia users through edit histories. In ICWSM '09, pages 106-113 (2009).

Lih, Andrew (2004). Wikipedia as participatory journalism: Reliable sources? metrics for evaluating collaborative media as a news resource. In 5th International Symposium on Online Journalism (2004).

Lih, Andrew (2009). The Wikipedia Revolution. Hyperion.

Lim, Sook; Kwon, Nahyun (2010). Gender differences in information behavior concerning Wikipedia, an unorthodox information source? Library 89 Information Science Research, 32 (3):212-220.

Lindsey, D. (2010). Evaluating quality control of wikipedia's feature articles. First Monday, 15 (4). URL: http://firstmonday.org/htbin/cgiwrap/bin/ojs/index.php/fm/article/view/ $2721 / 2482$.

Lipka, Nedim; Stein, Benno (2010). Identifying featured articles in wikipedia: writing style matters. In Proceedings of the 19th international conference on World wide web, WWW '10, pages 11471148, New York, NY, USA. ACM. 
Liu, X.; Iyer, B. (2007). Design architecture, developer networks and performance of open source software projects. In Proceedings of the Twenty-Eighth International Conference in Information Systems (2007). URL: http://www. softwareecosystems.com/design_architecture_people_ network.pdf.

Lopes, R.; Carriço, L. (2008). The impact of accessibility assessment in macro scale universal usability studies of the web. In W4A'08: Proceedings of the 2008 International Cross-Disciplinary Conference on Web Accessibility, W4A, pages 5-14 (2008).

Lovink, Geert; Tkacz, Nathaniel, editors (2011). Critical Point of View: A Wikipedia Reader. Institute of Network Cultures, Amsterdam.

Luyt, Brendan (2011). The nature of historical representation on wikipedia: Dominant or alterative historiography? Journal of the American Society for Information Science and Technology, 62(6): 1058-1065.

Luyt, Brendan; Aaron, Tay Chee Hsien; Thian, Lim Hai; Hong, Cheng Kian (2008). Improving wikipedia's accuracy: Is edit age a solution? Journal of the American Society for Information Science and Technology, 59(2):318-330.

Luyt, Brendan; Tan, Daniel (2010). Improving wikipedia's credibility: References and citations in a sample of history articles. Journal of the American Society for Information Science and Technology, 61(4):715-722.

Magnus, P.D. (2006). Epistemology and the wikipedia. North American Computing and Philosophy Conference Troy.

Magnus, P.D. (2008). Early response to false claims in wikipedia. First Monday, 13(9). URL: http: //firstmonday .org/htbin/cgiwrap/bin/ojs/index.php/fm/article/view/2115/2027.

Maillart, T.; Sornette, D.; Spaeth, S.; Krogh, von G. (2008). Empirical Tests of Zipf's Law Mechanism in Open Source Linux Distribution. Physical Review Letters, 101:218701. 
Mallan, Kerry; Giardina, Natasha (2009). Wikidentities: Young people collaborating on virtual identities in social network sites. First Monday, 14(6). URL: http://firstmonday.org/htbin/ cgiwrap/bin/ojs/index.php/fm/article/view/2445/2213.

March, J. G.; Simon, H. (1958). Organizations. Wiley, New York.

Marwell, Gerald; Oliver, Pamela (1993). The Critical Mass in Collective Action: A Micro-Social Theory. Cambridge University Press, Cambridge.

Matei, S. A.; Dobrescu, C. (2011). Wikipedia's "neutral point of view": Settling conflict through ambiguity. Information Society, 27(1):40-51.

Mattus, M. (2009). Wikipedia - free and reliable?: Aspects of a collaboratively shaped encyclopaedia. Nordicom Review, 30(1):183-199. URL: http://www.nordicom.gu.se/common/publ_pdf/ 279_mattusol.pdf.

McGrath, J. (1991). Time, Interaction, and Performance (TIP): A Theory of Groups. Small Group Research, 22(2):147-174.

Mcguinness, Deborah L.; Zeng, Honglei; Silva, Paulo Pinheiro Da; Ding, Li; Narayanan, Dhyanesh; Bhaowal, Mayukh (2006). Investigation into trust for collaborative information repositories: A wikipedia case study. In In Proceedings of the Workshop on Models of Trust for the Web, pages 3-131 (2006).

Merriam, Sharan B.; Courtenay, Bradley; Baumgartner, Lisa (2003). On Becoming a Witch: Learning in a Marginalized Community of Practice. Adult Education Quarterly, 53(3):170-188.

Miller, Nora (2005). Wikipedia and The Disappearing "Author". ETC: A Review of General Semantics, 62(1):37-40.

Mintzberg, H. (2007). Tracking strategies: Toward a general theory. Oxford University Press, Oxford, England.

Mintzberg, H.; McHugh, A. (1985). Strategy formation in an adhocracy. Administrative Science Quarterly, 30(2):160-197. 
Morgan, Jonathan T.; Mason, Robert M.; Nahon, Karine (2011). Lifting the veil: The expression of values in online communities. In ACM International Conference Proceeding Series, pages 8-15 (2011).

Mühlhauser, Ingrid; Oser, Friederike (2008). Does Wikipedia provide evidence based health care information? A content analysis. Zeitschrift für Evidenz, Fortbildung und Qualität im Gesundheitswesen, 102(7):e1 - e7. Shared Decision-Making in Health Care.

Müller-Seitz, Gordon; Reger, Guido (2009). Is open source software living up to its promises? insights for open innovation management from two open source software-inspired projects. $R \& D$ Management, 39(4):372-381.

Müller-Seitz, Gordon; Reger, Guido (2010). 'wikipedia, the free encyclopedia' as a role model? lessons for open innovation from an exploratory examination of the supposedly democraticanarchic nature of wikipedia. International Journal of Technology Management, 52(3-4):457-476.

Murley, Diane (2008). In defense of wikipedia. Law Library Journal, 100:593-600.

Musicant, David R.; Ren, Yuqing; Johnson, James A.; Riedl, John (2011). Mentoring in Wikipedia: A Clash of Cultures. In Proceedings of the 7th International Symposium on Wikis and Open Collaboration, WikiSym '11, New York, NY, USA. ACM.

Nagar, Yiftach (2012). What do you think?: the structuring of an online community as a collectivesensemaking process. In Proceedings of the ACM 2012 conference on Computer Supported Cooperative Work, CSCW '12, pages 393-402, New York, NY, USA. ACM.

Nazir, F.; Takeda, H. (2008). Extraction and analysis of tripartite relationships from wikipedia. In International Symposium on Technology and Society, Proceedings (2008).

Nemoto, Keiichi; Gloor, Peter; Laubacher, Robert (2011). Social capital increases efficiency of collaboration among wikipedia editors. In Proceedings of the 22nd ACM conference on Hypertext and hypermedia, HT '11, pages 231-240, New York, NY, USA. ACM. 
Niederer, Sabine; Dijck, van José (2010). Wisdom of the crowd or technicity of content? Wikipedia as a sociotechnical system. New Media $\& 3$ Society, 12(8):1368-1387.

Nielsen, F. A. (2007). Scientific citations in wikipedia. First Monday, 12(8). URL: http:// firstmonday.org/htbin/cgiwrap/bin/ojs/index.php/fm/article/view/1997/1872.

Nov, Oded (2007). What motivates wikipedians? Communications of the ACM, 50:60-64.

Okoli, Chitu (2009). A brief review of studies of wikipedia in peer-reviewed journals. International Conference on the Digital Society, 0:155-160.

Okoli, Chitu; Mehdi, Mohamad; Mesgari, Mostafa; Nielsen, Finn Å.; Lanamäki, Arto (2012). The People's Encyclopedia Under the Gaze of the Sages: A Systematic Review of Scholarly Research on Wikipedia. Technical report. URL: http://ssrn. com/paper=2021326.

Okoli, Chitu; Oh, Wonseok (2007). Investigating recognition-based performance in an open content community: A social capital perspective. Information $\&$ Management, 44:240-252.

Oliver, P.; Marwell, G.; Teixeira, R. (1985). A theory of critical mass interdependence, group heterogeneity, and the production of collective action. American Journal of Sociology, 91(3): $522-556$.

Olleros, F. X. (2008). Learning to trust the crowd: Some lessons from wikipedia. In Proceedings 2008 International MCETECH Conference on e-Technologies, MCETECH 2008, pages 212-216 (2008).

Olson, M. (1965). The logic of Collective Action. Harvard University Press, Cambridge Mass.

O'Neil, Mathieu (2010). Shirky and sanger, or the costs of crowdsourcing. JCOM, Journal of science communication, 9. URL: http://jcom.sissa.it/archive/09/01/Jcom0901\%282010\% $29 \mathrm{C} 01 / \mathrm{Jcom} 0901 \% 282010 \% 29 \mathrm{C} 04$.

Ortega, Felipe (2009). Wikipedia: A quantitative analysis. Doctoral thesis, Universidad Rey Juan Carlos, Móstoles, Spain, 228 pages. 
Ortega, Felipe; Gonzalez Barahona, Jesus M. (2007). Quantitative analysis of the wikipedia community of users. In Proceedings of the 2007 international symposium on Wikis, WikiSym '07, pages 75-86, New York, NY, USA. ACM.

Ortega, F.; Gonzalez-Barahona, J. M.; Robles, G. (2008). On the inequality of contributions to wikipedia. In Proceedings of the Annual Hawaii International Conference on System Sciences (2008).

Ortega, Felipe; Izquierdo-Cortazar, Daniel (2009). Survival analysis in open development projects. In Proceedings of the 2009 ICSE Workshop on Emerging Trends in Free/Libre/Open Source Software Research and Development, FLOSS '09, pages 7-12, Washington, DC, USA. IEEE Computer Society.

Ortega, Felipe; Izquierdo-Cortazar, Daniel; Gonzalez-Barahona, Jesus M.; Robles, Gregorio (2009). On the analysis of contributions from privileged users in virtual open communities. In 42th Hawaii International Conference on System Sciences (HICSS), page 110, Waikoloa, Big Island, Hawaii, USA. IEEE Computer Society.

Otto, Peter; Simon, Martin (2008). Dynamic perspectives on social characteristics and sustainability in online community networks. System Dynamics Review, 24(3):321-347.

Panciera, Katherine; Halfaker, Aaron; Terveen, Loren (2009). Wikipedians are born, not made: a study of power editors on wikipedia. In Proceedings of the ACM 2009 international conference on Supporting group work, GROUP '09, pages 51-60, New York, NY, USA. ACM.

Park, Taemin Kim (2011). The visibility of wikipedia in scholarly publications. First Monday, 16(8). URL: http://firstmonday.org/htbin/cgiwrap/bin/ojs/index.php/fm/ article/viewArticle/3492/303.

Pentzold, C. (2009). Fixing the floating gap: The online encyclopaedia wikipedia as a global memory place. Memory Studies, 2(2):255-272. 
Pentzold, Christian (2011). Imagining the wikipedia community: What do wikipedia authors mean when they write about their "community"? New Media 63 Society, 13(5):704-721.

Perovic, S. (2011). The intelligible as a new world? wikipedia versus the eighteenth-century encyclopédie. Paragraph, 34(1):12-29.

Pfeil, U.; Zaphiris, P.; Ang, C. S. (2006). Cultural differences in collaborative authoring of wikipedia. Journal of Computer-Mediated Communication, 12(1):88-113.

Pfister, Damien S. (2011). Networked expertise in the era of many-to-many communication: On wikipedia and invention. Social Epistemology, 25(3):217-231.

Poderi, Giacomo (2009). Comparing featured article groups and revision patterns correlations in wikipedia. First Monday, 14(5). URL: http://firstmonday.org/htbin/cgiwrap/bin/ojs/ index.php/fm/article/view/2365/2182.

Prasarnphanich, P.; Wagner, C. (2009). The role of wiki technology and altruism in collaborative knowledge creation. Journal of Computer Information Systems, 49(4):33-41.

Prasarnphanich, Pattarawan; Wagner, Christian (2011). Explaining the sustainability of digital ecosystems based on the wiki model through critical-mass theory. IEEE Transactions on Industrial Electronics, 58(6).

Preece, Jennifer; Shneiderman, Ben (2009). The reader-to-leader framework: Motivating technology-mediated social participation. AIS Transactions on Human-Computer Interaction, $1(1): 13-32$.

Pressley, Lauren; McCallum, Carolyn J. (2008). Putting the library in wikipedia. Online, 32(5): $39-42$.

Priedhorsky, R.; Chen, J.; Lam, S. K.; Panciera, K.; Terveen, L.; Riedl, J. (2007). Creating, destroying, and restoring value in Wikipedia. In GROUP'07 - Proceedings of the 2007 International ACM Conference on Supporting Group Work, pages 259-268 (2007). 
Rafaeli, S.; Ariel, Y. (2008). Online motivational factors: Incentives for participation and contribution in Wikipedia, In Barak, A., editor, Psychological aspects of cyberspace: Theory, research, applications, pages 243-267. Cambridge University Press, Cambridge.

Rahman, M. (2008). An Analysis of Wikipedia. Journal of Information Technology Theory and Application, 9:81.

Ransbotham, Sam; Kane, Gerald C. (2011). Membership turnover and collaboration success in online communities: Explaining rises and falls from grace in wikipedia. MIS Quarterly, 14(9): $541-545$.

Ransbotham, Sam; Kane, Gerald C.; Lurie, Nicholas H. (2012). Network characteristics and the value of collaborative user-generated content. Marketing Science. URL: http://mktsci. journal . informs .org/content/early/2012/01/24/mksc. 1110.0684. abstract.

Rask, Morten (2008). The reach and richness of wikipedia: Is wikinomics only for rich countries? First Monday, 13(6).

Ratkiewicz, J.; Fortunato, S.; Flammini, A.; Menczer, F.; Vespignani, A. (2010). Characterizing and modeling the dynamics of online popularity. Physical Review Letters, 105(15).

Reagle Jr., Joseph Michael (2010). Good Faith Collaboration. The Culture of Wikipedia. MIT Press, Cambridge, Massachusetts.

Reagle Jr., J. M. (2010b). "be nice": Wikipedia norms for supportive communication. New Review of Hypermedia and Multimedia, 16(1-2):161-180.

Rector, Lucy Holman (2008). Comparison of wikipedia and other encyclopedias for accuracy, breadth, and depth in historical articles. Reference Services Review, 36(1):7 - 22.

Roberts, Peter; Peters, Michael A. (2011). From castalia to wikipedia: openness and closure in knowledge communities. E-Learning and Digital Media, 8(1):36-46.

Rosenzweig, Roy (2006). Can history be open source? wikipedia and the future of the past. The Journal of American History, 93(1):117-146. 
Rossi, A.; Gaio, L.; Den Besten, M.; Dalle, J. . (2010). Coordination and division of labor in open content communities: The role of template messages in wikipedia. In Proceedings of the Annual Hawaii International Conference on System Sciences (2010).

Royal, Cindy; Kapila, Deepina (2009). What's on wikipedia, and what's not . . ? Social Science Computer Review, 27(1):138-148.

Santana, Adele; Wood, Donna (2009). Transparency and social responsibility issues for wikipedia. Ethics and Information Technology, 11:133-144.

Scacchi, Walt (2007). Free/open source software development: recent research results and emerging opportunities. In ESEC-FSE companion 07: The 6th Joint Meeting on European software engineering conference and the ACM SIGSOFT symposium on the foundations of software engineering, pages 459-468, New York, NY, USA. ACM.

Schilling, A.; Laumer, S.; Weitzel, T. (2012). Who will remain? an evaluation of actual person-job and person-team fit to predict developer retention in floss projects. In 45 th Hawai'i International Conference on System Sciences, pages 3446-3455 (2012).

Schroer, J.; Hertel, G. (2009). Voluntary engagement in an open web-based encyclopedia: Wikipedians and why they do it. Media Psychology, 12(1):96-120.

Seddon, P. B. (1997). A respecification and extension of the delone and mclean model of is success. Information Systems Research, 8(3):240-253.

Shachaf, P.; Hara, N. (2010). Beyond vandalism: Wikipedia trolls. Journal of Information Science, $36(3): 357-370$.

Shah, Sonali K. (2006). Motivation, governance, and the viability of hybrid forms in open source software development. Management Science, 52(2):1000-1014.

Silva, F. N.; Viana, M. P.; Travençolo, Bruno Augusto Nassif; Fontoura Costa, da Luciano (2011). Investigating relationships within and between category networks in wikipedia. Journal of Informetrics, 5(3):431-438. 
Simon, H. (1957). Adminsitrative behavior. MacMillan.

Slattery, Shaun (2009). "edit this page": The socio-technological infrastructure of a wikipedia article. In SIGDOC'09 - Proceedings of the 27th ACM International Conference on Design of Communication, pages 289-295 (2009).

Soekatno, Revo; Giri, Arka (2005). The indonesian language wikipedia. In Wikimania05 (2005). URL: http://meta.wikimedia.org/wiki/Transwiki:Wikimania05/Paper-RS1.

Spoerri, Anselm (2007a). Visualizing the overlap between the 100 most visited wikipedia pages in september 2006 to february 2007. First Monday, 12(4). URL: http://firstmonday .org/htbin/ cgiwrap/bin/ojs/index.php/fm/article/view/1764/1644.

Spoerri, Anselm (2007b). What is popular on wikipedia and why? First Monday, 12(4). URL: http://www .uic.edu/htbin/cgiwrap/bin/ojs/index.php/fm/article/view/1765/1645.

Stankus, T.; Spiegel, S. E. (2010a). Wikipedia, scholarpedia, and references to books in the brain and behavioral sciences: A comparison of cited sources and recommended readings in matching free online encyclopedia entries (1). Science and Technology Libraries, 29(1-2):144-164.

Stankus, T.; Spiegel, S. E. (2010b). Wikipedia, scholarpedia, and references to journals in the brain and behavioral sciences: A comparison of cited sources and recommended readings in matching free online encyclopedia entries (2). Science and Technology Libraries, 29(3):258-265.

Stein, Klaus; Hess, Claudia (2007). Does it matter who contributes - a study on featured articles in the german wikipedia. In Hypertext 2007: Proceedings of the Eighteenth ACM Conference on Hypertext and Hypermedia, HT'07, pages 171-174 (2007).

Stvilia, Besiki; Al-Faraj, A.; Yi, Y. (2009). Issues of cross-contextual information quality evaluationthe case of arabic, english, and korean wikipedias. Library $\& 3$ Information Science Research, 31 (4):232-239.

Stvilia, Besiki; Gasser, L. (2008). An activity theoretic model for information quality change. First 
Monday, 13(4). URL: http://www.firstmonday .org/htbin/cgiwrap/bin/ojs/index.php/fm/ article/view/2126/1951.

Stvilia, B.; Gasser, L.; Twidale, M. B.; Smith, L. C. (2007). A framework for information quality assessment. Journal of the American Society for Information Science and Technology, (12):17201733.

Stvilia, Besiki; Twidale, Michael B.; Smith, Linda C.; Gasser, Les (2008). Information quality work organization in wikipedia. Journal of the American Society for Information Science and Technology, 59(6):983-1001.

Suh, B.; Convertino, G.; Chi, E. H.; Pirolli, P. (2009). The singularity is not near: Slowing growth of wikipedia. In Proceedings of the 5th International Symposium on Wikis and Open Collaboration, WiKiSym 2009 (2009).

Sundin, Olof (2011). Janitors of knowledge: constructing knowledge in the everyday life of Wikipedia editors. Journal of Documentation, 67(5):840-862.

Surowiecki, James (2004). The Wisdom of Crowds: Why the Many Are Smarter Than the Few and How Collective Wisdom Shapes Business, Economies, Societies and Nations. Doubleday, Anchor.

Svoboda, Elizabeth (2006). One-click content, no guarantees. IEEE Spectrum, 43:64-65. URL: http://spectrum.ieee.org/telecom/internet/oneclick-content-no-guarantees.

Swarts, Jason (2009). The collaborative construction of 'fact' on wikipedia. In SIGDOC'09 Proceedings of the 27th ACM International Conference on Design of Communication, pages 281$288(2009)$.

Swartz, Aaron (2006). Who writes Wikipedia? URL: http://www.aaronsw.com/weblog/ whowriteswikipedia.

Taraborelli, D.; Ciampaglia, G. L. (2010). Beyond notability. collective deliberation on content inclusion in wikipedia. In Proceedings - 2010 4th IEEE International Conference on Self-Adaptive and Self-Organizing Systems Workshop, SASOW 2010, pages 122-125 (2010). 
Thom-Santelli, Jennifer; Cosley, Dan R.; Gay, Geri (2009). What's mine is mine: territoriality in collaborative authoring. In Proceedings of the 27th international conference on Human factors in computing systems, CHI '09, pages 1481-1484, New York, NY, USA. ACM. ISBN 978-1-60558246-7.

Turek, P.; Wierzbicki, A.; Nielek, R.; Hupa, A.; Datta, A. (2010). Learning About the Quality of Teamwork from Wikiteams. In IEEE Second International Conference on Social Computing (SocialCom), pages $17-24$ (2010).

Ung, Hang; Dalle, Jean-Michel (2010). Project management in the wikipedia community. In Proceedings of the 6th International Symposium on Wikis and Open Collaboration, WikiSym '10, pages 13:1-13:4, New York, NY, USA. ACM.

Uzzi, Brian (2008). A social network's changing statistical properties and the quality of human innovation. Journal of Physics A: Mathematical and Theoretical, 41(22):224023, 12pgs.

Uzzi, Brian; Spiro, Jarrett (2005). Collaboration and creativity: The small world problem. American Journal of Sociology, 111(2):447-504.

Dijk, van Z (2009). Wikipedia and lesser-resourced languages. Language Problems and Language Planning, 33(3):234-250.

Venkatesh, V.; Morris, M. G.; Davis, G. B.; Davis, F.D. (2003). User acceptance of information technology: Toward a unified view. MIS Quarterly, 27(3):425-478.

Viégas, F. B. (2007). The visual side of wikipedia. In Proceedings of the Annual Hawaii International Conference on System Sciences (2007).

Viégas, Fernanda B.; Wattenberg, Martin; K., Dave; (2004). Studying cooperation and conflict between authors with history flow visualizations. In Proceedings of $\mathrm{CHI} 2004$, pages 575-582. ACM Press (2004).

Viégas, Fernanda B.; Wattenberg, Martin; Kriss, J.; Ham, van F. (2007a). Talk before you type: Coordination in wikipedia. In Proceedings of HICSS 2007, pages 78-87 (2007a). 
Viégas, Fernanda B.; Wattenberg, Martin; McKeon, Matthew M. (2007b). The hidden order of wikipedia. In Proceedings of the 2nd international conference on Online communities and social computing, OCSC'07, pages 445-454, Berlin, Heidelberg. Springer-Verlag.

Voss, Jakob (2005). Measuring Wikipedia. In Proceedings of the International Conference of the International Society for Scientometrics and Informetrics (ISSI), 10, Stockholm.

Wallace, D.; Van Fleet, C. (2005). The democratization of information? wikipedia as a reference resource. Reference and User Services Quarterly, 45:100-103.

Wang, J.; Jin, X.; Wu, Y.-P. (2009). An empirical study of knowledge collaboration networks in virtual community: Based on wiki. In 2009 International Conference on Management Science and Engineering - 16th Annual Conference Proceedings, ICMSE 2009, pages 1092-1097 (2009).

Wang, J.; Ma, F.; Cheng, J. (2010). The impact of research design on the half-life of the wikipedia category system. In 2010 International Conference on Computer Design and Applications, ICCDA 2010, volume 4, pages V498-V4102 (2010).

Waters, Neil L. (2007). Why you can't cite wikipedia in my class. Communnications of the ACM, $50: 15-17$.

Welser, Howard T.; Cosley, Dan; Kossinets, Gueorgi; Lin, Austin; Dokshin, Fedor; Gay, Geri; Smith, Marc (2011). Finding social roles in wikipedia. In Proceedings of the 2011 iConference, iConference '11, pages 122-129, New York, NY, USA. ACM.

West, Andrew G.; Lee, Insup (2011). What wikipedia deletes: characterizing dangerous collaborative content. In Proceedings of the 7th International Symposium on Wikis and Open Collaboration, pages $25-28$ (2011).

West, Kathy; Williamson, Janet (2009). Wikipedia: friend or foe? Reference Services Review, 37 (3):260 - 271.

Wielsch, Dan (2010). Governance of massive multiauthor collaboration - linux, wikipedia, and other 
networks: Governed by bilateral contracts, partnerships, or something in between? JIPITEC, 1: $96-108$.

Wilkinson, Dennis M.; Huberman, Bernardo A. (2007). Assesssing the value of cooperation in wikipedia. First Monday, 12(4). URL: http://www.firstmonday.org/htbin/cgiwrap/bin/ ojs/index.php/fm/article/view/1763/.

Wöhner, Thomas; Peters, Ralf (2009). Assessing the quality of Wikipedia articles with lifecycle based metrics. In WikiSym '09: Proceedings of the 5th International Symposium on Wikis and Open Collaboration, pages 1-10, New York, NY, USA. ACM.

Xu, J.; Yilmaz, L.; Zhang, J. (2008). Agent simulation of collaborative knowledge processing in wikipedia. In Proceedings of the 2008 Spring Simulation Multiconference, SpringSim'08, pages 19-25 (2008).

Yang, Heng-Li; Lai, Cheng-Yu (2010). Motivations of Wikipedia content contributors. Computers in Human Behavior, 26(6):1377 - 1383.

Yasseri, Taha; Sumi, Robert; Kertséz, János (2012). Circadian patterns of wikipedia editorial activity: A demographic analysis. PLoS ONE, 7(1). URL: http://www.plosone.org/article/ info\%3Adoi\%2F10.1371\%2Fjournal . pone.0030091\#pone.0030091-Jonathan1.

Zhang, Xiaoquan; Zhu, Feng (2011). Group size and incentives to contribute: A natural experiment at chinese wikipedia. The American Economic Review, 101(4):1601-1615.

Zhang, Y.; Sun, A.; Datta, A.; Chang, K.; Lim, E. . (2010). Do wikipedians follow domain experts?: A domain-specific study on wikipedia knowledge building. In Proceedings of the ACM International Conference on Digital Libraries, pages 119-128 (2010).

Zhao, Xiaoli; Bishop, M. (2011). Understanding and supporting online communities of practice: lessons learned from wikipedia. Educational Technology Research and Development, 59:711-735.

Zhu, Haiyi; Kraut, Robert; Kittur, Aniket (2012). Effectiveness of shared leadership in online 
communities. In Proceedings of the ACM 2012 conference on Computer Supported Cooperative Work, CSCW '12, pages 407-416, New York, NY, USA. ACM.

Zhu, Haiyi; Kraut, Robert E.; Wang, Yi-Chia; Kittur, Aniket (2011). Identifying shared leadership in Wikipedia. In Proceedings of the 2011 annual conference on Human factors in computing systems, CHI '11, pages 3431-3434, New York, NY, USA. ACM.

Zlatić, V.; Bozicević, M.; Stefancić, M., H.and Domazet (2006). Wikipedias: collaborative webbased encyclopedias as complex networks. Phys Rev E, 74:016115.

Zube, Paul; Velasquez, Alcides; Ozkaya, Elif; Lampe, Cliff; Obar, Jonathan (2012). Classroom wikipedia participation effects on future intentions to contribute. In Proceedings of the ACM 2012 conference on Computer Supported Cooperative Work, CSCW '12, pages 403-406, New York, NY, USA. ACM. 